\title{
Vertical hydraulic conductivity of riverbank and hyporheic zone sediment at Muda River riverbank filtration site, Malaysia
}

\author{
Mohd Khairul Nizar Shamsuddin ${ }^{1,2}$ (D) Wan Nor Azmin Sulaiman² ${ }^{2}$ Mohammad Firuz Ramli . \\ Faradiella Mohd Kusin ${ }^{2}$
}

Received: 4 November 2017 / Accepted: 21 November 2018 / Published online: 14 December 2018

(c) The Author(s) 2018

\begin{abstract}
In analysing the stream-aquifer interactions and riverbank filtration (RBF) systems, it is very crucial to determine the vertical riverbank and streambed hydraulic conductivity. The riverbank and streambed focused in this investigation are a riverbank of six layers with depths of $38 \mathrm{~m}$ and streambed with depths of $9 \mathrm{~m}$ connected layers of sediments at 22 test locations and 4 test wells in the Muda River, Malaysia. In the analysis, there were a few tests involved to determine riverbank and hydraulic conductivity of vertical streambed, such as analysis of grain size, pumping test and in situ falling head standpipe permeability tests. The approximate $K$ values of 114 samples and 15 samples taken from riverbanks and streambeds, respectively, were then calculated by employing empirical equation methods [Hazen, Hazen $K(\mathrm{~cm} / \mathrm{s})=d 10(\mathrm{~mm})$, Terzaghi, Beyer, Slichter, Sauerbrei, Kruger, Kozeny-Carman, Zunker, USBR, Zamarin, Barr, Alyamani and Sen, Chapuis, and Krumbein and Monk]. The geometric mean of $K$ for six layers, namely the sandy silt $(8.30 \mathrm{~m} /$ day $)$, silty sand $(47.66 \mathrm{~m} /$ day $)$, gravelly sand $(150.24 \mathrm{~m} /$ day $)$, sandy gravel layer $(418.48 \mathrm{~m} /$ day $)$, gravelly sand $(151.09 \mathrm{~m} /$ day $)$ and silty clay $(9.36 \mathrm{~m} /$ day $)$ as identified characteristics by using grain-size analyses, was greater than the $K$ of pumping test (geometric mean) ( $31.10 \mathrm{~m} /$ day) and the mean obtained from $K$ of permeability tests $(7.03 \mathrm{~m} /$ day). In general, the $K$ values of upper layer of sediments of streambed were recorded to be larger in comparison with their respective lower layer of sediments. The $K$ value for the upper layer of sediments from all tests located at the left, right and middle parts of the river ranged from 7.56 to $54.77 \mathrm{~m} /$ day for upper layer, from 39.80 to $128.40 \mathrm{~m} /$ day for middle layer and from 9.11 to $49.92 \mathrm{~m} /$ day for lower layer, as described by the grain-size analysis. The value of $K$ ranges based on permeability test indicated that the value of $K$ was from 0.036 to $1.09 \mathrm{~m} /$ day for the upper layer and 0.16 to $0.68 \mathrm{~m} /$ day for the lower layer of hyporheic sediments zone. Based on the acquired results, the conclusion that the aquifer of the focused area shows possibility for RBF and has the potential to improve the water quality and quantity is referable.
\end{abstract}

Keywords Grain-size analysis $\cdot$ Streambed $\cdot$ Riverbank $\cdot$ Hydraulic conductivity $\cdot$ Riverbank filtration $\cdot$ Malaysia

\section{Introduction}

Hyporheic zone is the transition zone between groundwater and surface water where it is mixed and exchanged in this zone (Brunke and Gonser 1997; Winter 1998; Smith 2005; Hester and Gooseff 2010). Hydrological, biological and

Mohd Khairul Nizar Shamsuddin

nizar@nahrim.gov.my

1 Hydrogeology Research Centre, National Hydraulic Research Institute of Malaysia, Lot 5377, Jalan Putra Permai, 43300 Seri Kembangan, Selangor, Malaysia

2 Faculty of Environmental Studies, Universiti Putra Malaysia, 43400 Serdang, Selangor, Malaysia chemical processes are the factors affected the interaction between the two types of water in the hyporheic zone (Winter 1998; Bencala et al. 2011; Bruno et al. 2009; Gariglio et al. 2013; Winter 1998; Kennedy et al. 2009; Binley et al. 2013). Thus, obtaining the intelligence of their interaction is very essential to investigate the feasibility site for riverbank filtration (RBF). RBF can be described as the transmission of river water through aquifer alluvium that allows the pumping test wells of the public water supply with higher quality as compared to river water (Shamsuddin et al. 2014). To determine the development and management of groundwater resources, the hydraulic parameters such as hydraulic conductivity $(K)$, transmissivity $(T)$, storativity $(S)$ and specific storage $\left(S_{\mathrm{s}}\right)$ must be firstly identified. The vertical 
hydraulic conductivity $(K)$ of riverbank and streambed is a key important parameter in the analysis of performance of RBF. In broader term, a porous medium ability to transmit water through its interconnected voids is defined as hydraulic. Establishing the $K$ parameter of riverbank and streambed is very essential in quantifying the flow and magnitude of fluxes exchange in hyporheic zone and water exchange degree and contamination transfer between surface water and groundwater. This parameter plays even greater role in the design of RBF, particularly in the aspects of conjunctive use of groundwater and surface water. As for this study, the inconsistency in $K$ 's estimations derived through different methods such as grain-size analysis, pumping tests and permeability tests became a challenge in evaluating the most representative value of the suitable field conditions. To develop and provide the fundamental data for numerical modelling, the $K$ estimates were firstly identified from these experiments before comparing them to the data from pumping test, permeability test and grain-size analysis (Shamsuddin et al. 2015). The outcomes from pumping tests often show valid $K$ values, but only with the presence of precise data of hydraulic boundaries and aquifer geometry (Uma et al. 1989). In comparison, Landon et al.'s study (2001) stated that Hvorslev permeameter test is significantly established in providing $K$ value than grain-size tests, as the former is field-test-oriented and does not rely on the empirical relationship between $K$ and grain size. However, the results from Cardenas and Zlotnik (2003)'s investigation which utilised multilevel slug test and grain-size analysis conducted in sandy streambeds provided reasonably similar $K$ estimates. The small-slug test was conducted to obtain $K$ value of a streambed containing of sand (Hinsby et al. 1992). Next, other methods employed in this paper were the flood waveresponse technique and numerical modelling to confirm the aquifer parameters and to apprehend the interaction of aquifer stream in a gravel of aquifer (Reynolds 1987). Additionally, Jha et al. (2004) also utilised the method of the flood wave-response technique in an alluvial aquifer, river-level fluctuate data and corresponding groundwater-level data to calculate $T$ and hydraulic diffusivity. In comparison, to obtain the suitable solution for stream depletion in nearby wells, Sophocleous et al. (1995) and Spalding and Khaleel (1991) adopted numerical modelling approaches in their studies. To be simply put, there were numerous previous studies that discussed a various of approaches and techniques to determine the value of streambed $\mathrm{K}$, which include the permeability test, slug and bail tests, grain size analysis and pumping test (Hvorslev 1951; Chen 2000, 2004, 2005a, b, 2007; Landon et al. 2001; Genereux et al. 2008; Kennedy et al. 2009; Springer et al. 1999; Ryan and Boufadel 2007; Leek et al. 2009, Chen 2000; Kelly and Murdoch 2003). Due to factors such as measurement scale and field conditions, it should be considered that each method has its own limitation
(Kalbus et al. 2006). For example, the results from slug and bail tests can only provide streambed horizontal hydraulic conductivity $\left(K_{\mathrm{h}}\right)$ values, while grain-size analysis test is unable to assess the anisotropy of $K$ values because the sediment structure is destroyed during sampling (Chen 2000; Kalbus et al. 2006; Cheng and Chen 2007). It has been suggested that permeability tests can produce more accurate streambed $K$ values than grain-size analysis and required less cost compared to pumping tests. The $K$ values will able to produce from grain-size analyses either horizontal or vertical aquifer properties, but sedimentary formations or other thin depositional layers are destroyed during sediment sampling. Besides, distortion of the texture of the in situ medium which occurred in grain-size analyses causes the outcome to be less authentic than pumping tests (Uma et al. 1989). Nevertheless, this method is still able to economically determine $K$ values. There have been several grain-size methods originally proposed by Hazen (1893), Beyer (1964), Schlichter (1899), Kozeny (1927), Sauerbrei (cited in Kasenow 2002) and Shepherd (1989). In the study conducted by Indelman et al. (1999), the $K$ estimation for sand layers at the Chalk River site, Ontario, Canada, was obtained by using grainsize methods, by which the result was then compared with a radiotracer test. Their research revealed that the differences between the tracer test and $K$ estimates of grain-size analysis were rather insignificant. Interestingly, Boadu (2000) adopted a different approach to estimate $K$ by utilising the methods of grain-size distribution, entropy of distribution and fractal dimension, soil density, porosity and fine grain content. The numerical modelling has been frequently employed in various investigations to estimate groundwaterlevel fluctuation that serves for abundant of purposes such as the development of groundwater, prevention of the decline of groundwater level and predicting outflow in tunnels or underground storage caverns. Thus, the importance of this tool for groundwater management is undebatable particularly in predicting groundwater level and storage changes (Senthil Kumar and Elango 2001). Researcher Mayer et al. (2002) also developed numerical models that served for two main purposes: to identify the storage coefficient in managing the interaction of surface water-groundwater during rapid river-stage fluctuations and to investigate how the storage coefficient affects groundwater contamination scenarios. Even though there are many available methods in identifying the hydraulic conductivities of unconsolidated sediments, there is none that provides unlimited application of mean, median and effective diameter (Kasenow2002). Nonetheless, grain-size methods are often preferred by researchers due to the low cost and less reliance on the hydraulic and geometry boundaries of the streambed, the qualities that significantly distinguish them from other methods (Alyamani and Sen 1993). Since the information regarding the characteristic properties of sediments is more attainable, sediments from 
grain-size distribution were estimated for hydraulic conductivity which is commonly favoured by researchers. Furthermore, streambed $K$ is anisotropic which is well known (Chen 2000; Landon et al. 2001). The vertical hydraulic conductivity $\left(K_{\mathrm{v}}\right)$ and horizontal hydraulic conductivity $\left(K_{\mathrm{h}}\right)$ can also be measured using appropriate tests (Chen 2000; Landon et al. 2001). Nonetheless, the setback in conducting the investigation is that the original sediment structure of the streambed is inevitably destroyed during sediment sampling. It is unfortunate that the grain-size analysis methods provide neither $K$ horizontal $\left(K_{\mathrm{h}}\right)$ nor $K$ vertical $\left(K_{\mathrm{v}}\right)$, and they also preclude any evaluation of anisotropy and/or differences in directional $K$ (Chen, 2000). Therefore, the values of streambed $K$ determined from grain-size analysis are bound to be significantly distinctive from either $K_{\mathrm{h}}$ or $K_{\mathrm{v}}$ values obtained from the use of other methods, such as permeability tests. To solve this, a number of researchers prioritised the measurement of $K_{\mathrm{v}}$ of streambed rather than $K_{\mathrm{v}}$ of riverbank. In this paper, the combination of $K_{\mathrm{v}}$ of riverbank and $K_{\mathrm{v}}$ from streambeds was employed to obtain the hydraulic conductivity of sediments derived from grain-size distribution. The focus of this paper is centred mainly on the distribution pattern of $K_{\mathrm{v}}$ on the riverbank and streambed. As to reach the objectives, riverbank and streambed permeability tests and grain-size analyses were managed in the hyporheic zone of the Muda River with depth. The aim of this study was to (1) investigate the unevenness in vertical hydraulic conductivity of riverbank and streambed $(K)$ with depth at small scale, (2) to analyse the empirical methods used individually in estimating the hydraulic conductivity $\left(K_{\mathrm{g}}\right)$ from riverbank and streambed sediments $\left(K_{\mathrm{gs}}\right)$ and differentiating the estimated values with measured values from pumping test $\left(K_{\mathrm{p}}\right)$ and permeability test $\left(K_{\mathrm{pt}}\right)$ and (3) to study the correlation between the distribution of sediment grain size and vertical hydraulic conductivity of the riverside alluvium in the Lower Muda River Basin RBF area located near to the Muda River.

\section{Study area}

The focused area in this paper, Muda River Basin, takes place in the north-western part of Peninsular Malaysia. The upper and middle river basins belong to the State of Kedah, and the downstream part of the river marks the border of the States of Kedah and Penang. Throughout the years, the river has been utilised as a valuable water resource for agriculture and water supply for Kedah and Penang states as both states have the rights to use water from the Muda River. The study area lies between $5^{\circ} 31^{\prime} 30^{\prime \prime}$ and $5^{\circ} 35^{\prime} 30^{\prime \prime}$ north latitude and $100^{\circ} 29^{\prime} 0^{\prime \prime} \mathrm{E}$ and $100^{\circ} 33^{\prime} 30^{\prime \prime} \mathrm{E}$ east longitudes, which in total covers an area of 150 sq.km (Fig. 1). The basin is of tropical climate, and the area receives rain under the influence of two typical monsoons, namely the south-west monsoon
(May-August) and north-east monsoon (November-February). During this period, the studied area gets the heaviest annual rainfall precipitation. In addition, both states have the average temperature of $27^{\circ} \mathrm{C}$. It is known that both Kedah and Penang are the states with important agricultural area in Malaysia, as they are widely acknowledged as the country's rice bowl. Hence, agriculture becomes their most significant economic activity, with paddy as the chief crops. It has the largest double cultivation paddy field which is the main food source among Malaysians. The Muda River basin meander is located between the states of Kedah and Pulau Pinang with a length of $180 \mathrm{~km}$ and a catchment area of $4210 \mathrm{~km}^{2}$ beginning from the Muda Dam and flows across the districts of Baling, Sik and Kuala Muda. This stream serves as the water supply for the industry, agriculture, services, tourism and paddy planting for both Kedah and Pulau Pinang. However, during the rainy season, which takes place in September-November and April-May every year, the basin is often flooded. The casualties caused by the flood worsen each year, namely the erosion of riverbank, reduction in water resources and river pollution. As of now, the flood occurred in October 2003 was dubbed as the worst one yet in comparison with previous events in 1988, 1995 and 1998. Nonetheless, this basin is still the crucial water supply for water consumptions, agriculture and industries for the residents of Kedah and Pulau Pinang states. It is also a source of fresh water, where there are 17 water intake schemes in four districts of the basin.

\section{Geological of the study area}

The Muda River meanders from east to west, crossing the northern boundary of RBF site. The site focused in the study is generally located in a Quaternary deposit area. The alluvial layers in the study area are composed of upper layer of fine sands and lower layer of a highly conductive sandy gravel layer. By analysing the sample data from boreholes MW1-MW22 (riverbank), RB1-RB3, RVB1 and RVB2 (streambed) and the drill data from pumping wells TW1-TW4, the alluvial layers were then identified. The pumping wells and piezometer were screened at the sandy gravel layer to the bottom. The identification of the profile of the alluvial layers relied heavily on the data from piezometers $\mathrm{BH} 1-\mathrm{BH} 22$. The sandy gravel layer that is the main aquifer has an average thickness of $24 \mathrm{~m}$. Since the upstream of Muda River is placed on continental deposit, the stream's parent's materials largely made up of clay, silt, sand and gravels (Fig. 2). These unconsolidated sediments in this area are usually associated with traces of sand and organic matter and generally thicken seawards. The downstream area of Muda River, situated in the northern part of Muda River, is located in meta-sedimentary rocks and was reported to be of the Ordovician-Silurian age. It consists of phyllite, 


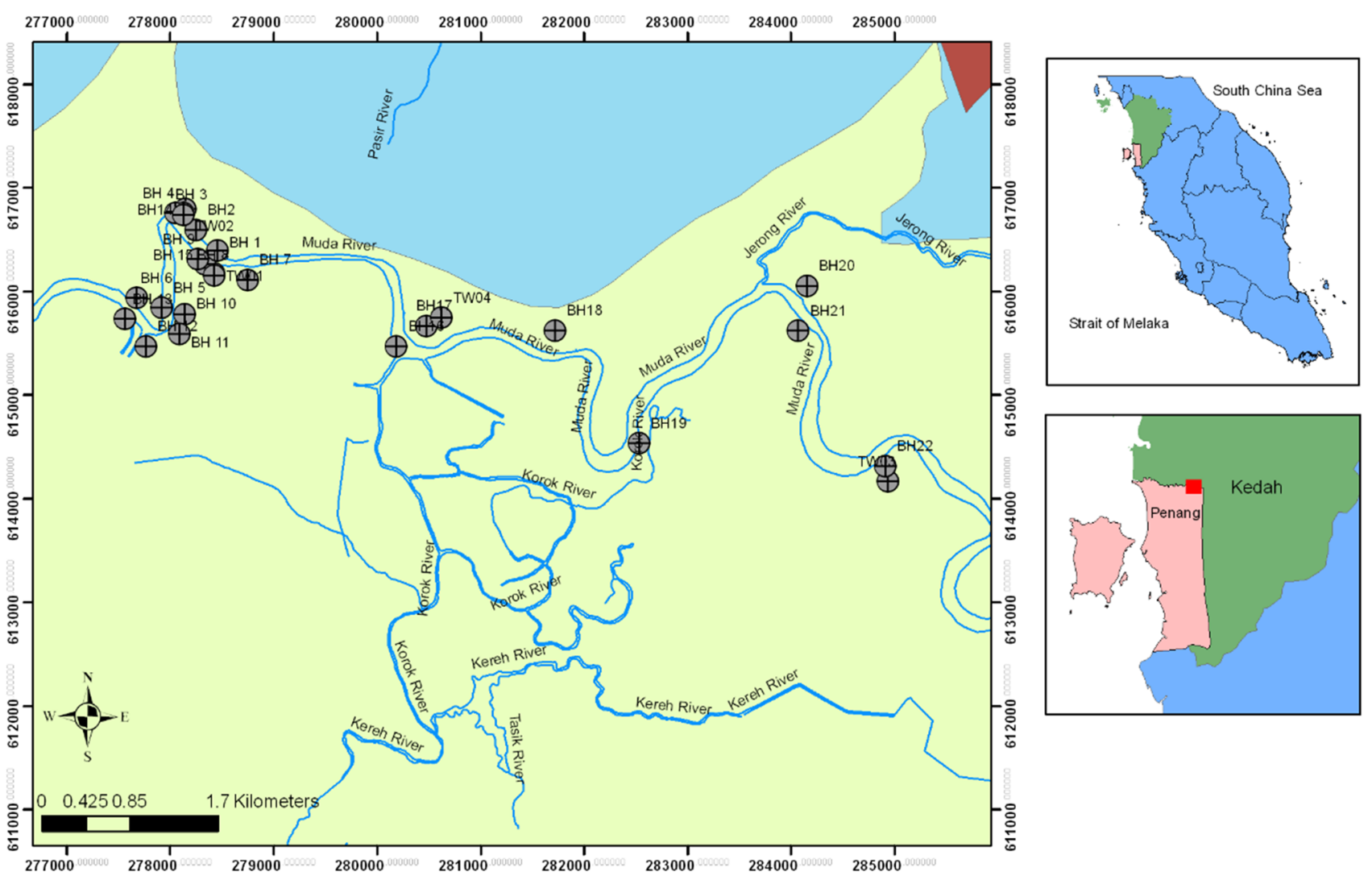
Legend
Lithology
Symbols
Clay, silt, sand and gravel
Study Area
Interbedded sandstone, siltstone and shale; widespread volcanics
Schist, phyllite, slate and limestone. Minor intercalations of sandstone and volcanics.
$\oplus$ Well Location
River

Fig. 1 Geology and location of the study area located at two states Penang and Kedah

slate and schist with minor intercalation of sandstone forming a thin layer. These meta-sedimentary rocks are formed subsequently after the mild and regional metamorphic event towards the original formation. As an outcome, this process results in the reformations of shale to schist/phyllite/ slate. The sequences of metamorphic rock from low to high metamorphic grade are in the order of slate, phyllite and schist. The higher grade of metamorphic rocks indirectly indicates greater changes in mineral composition and orientation, in addition to the decrease in the material's strength. The same action has caused mica minerals to be oriented in one direction and formed as weak planes. The schist is quite complex in nature with respect to inhomogeneous and treacherous weathering profile. These high-grade metamorphic rocks provide weak foliation planes, which are normally not parallel to the bedding planes. Commonly, these foliation planes control the discontinuities in meta-sediment rocks. Nonetheless, there is no major fault detected along the Muda River area based on the geological map of Peninsular Malaysia.

\section{Materials and methods}

\section{Sediment sampling and grain-size analysis}

In order to firstly establish the geological profile of an aquifer system, 129 different soil samples were extricated from test holes during an ongoing drilling project. The samples were collected from the cuttings and were sent to the laboratory for further analysis. Afterwards, all the samples were tested and experimented for grain-size distribution using the standard procedures of BS1377. Samples with coarser particles were analysed by using the dry sieve analysis which operated on a series of sorted BS sieves. On the other hand, 


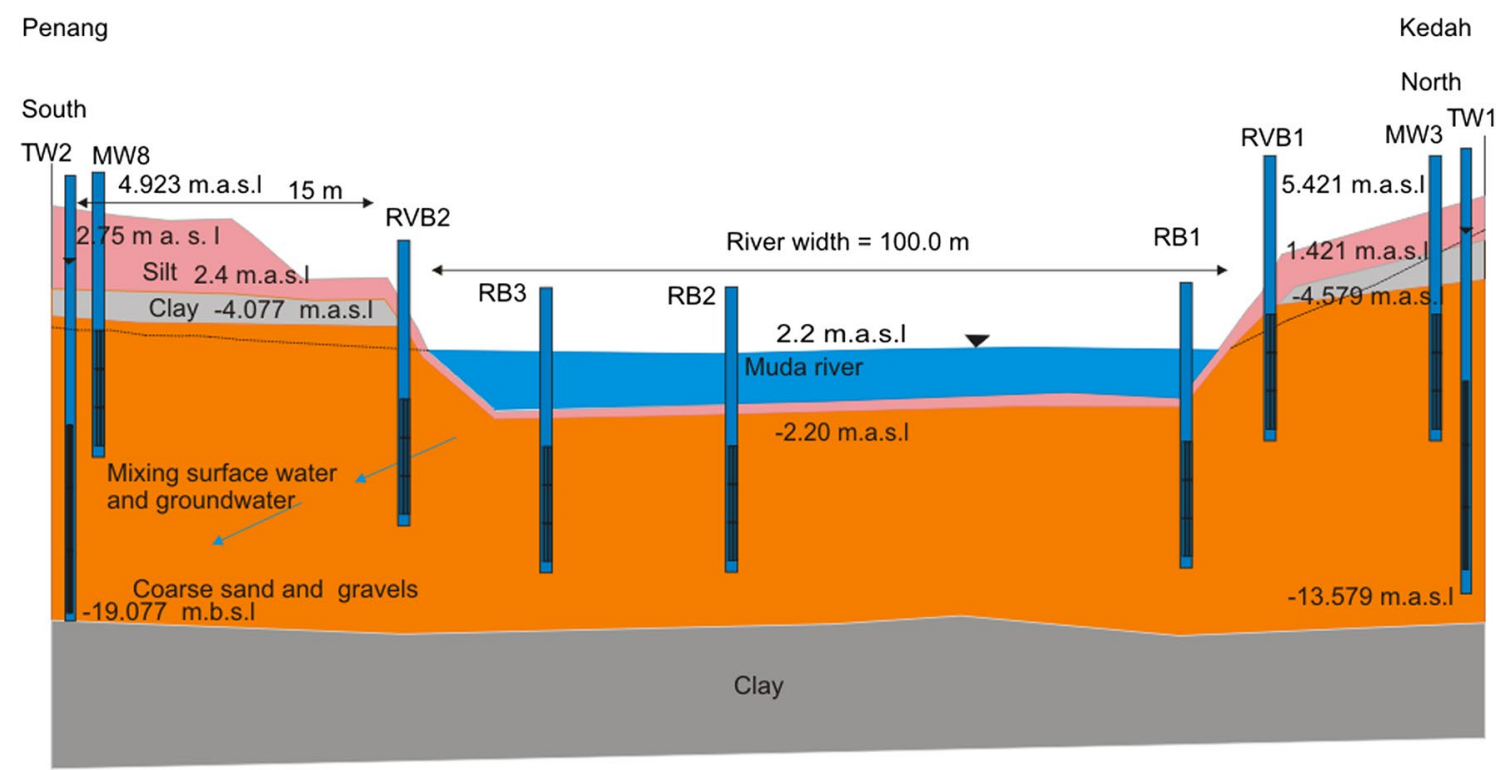

Fig. 2 Schematic hydrogeological cross sections, illustrating the riverbank and streambed in Muda River Basin

hydrometer method was utilised to observe the finer samples. This test is important as to pinpoint the percentage of different grain sizes contained from BH1 to BH22, TW1 to TW4 and riverbed soil (right river, middle river and left river). On that note, it should be mentioned that the methods and analyses performed in this investigation closely followed the British Standard 1377: Part2: 1990. Generally, the sieve analysis or mechanical analysis is commonly performed to ascertain the distribution of the coarser, large-sized particles, while the hydrometer method is employed to identify the distribution of the finer particles. As to get more accurate analysis, the study continued with the measurement of the initial mass of the soil in the container before it was soaked in distilled water for $24 \mathrm{~h}$. After that, the soil was washed using $63-\mu \mathrm{m}$ sieve until the water was clear. The remaining soil on that sieve was dried in the oven for $24 \mathrm{~h}$ and weighed again before the sieve analysis was employed. In this observation, the sieves were fixed in the order of $114 \mathrm{~mm}, 10 \mathrm{~mm}$, $6.3 \mathrm{~mm}, 5.0 \mathrm{~mm}, 3.35 \mathrm{~mm}, 2.0 \mathrm{~mm}, 1,18 \mathrm{~mm}, 600 \mu \mathrm{m}$, $425 \mu \mathrm{m}, 300 \mu \mathrm{m}, 212 \mu \mathrm{m}, 150 \mu \mathrm{m}$ and $63 \mu \mathrm{m}$. Subsequently, the weight of the retained soil on each sieve was measured after completing the shaking process in $10 \mathrm{~min}(63 \mu \mathrm{m})$. The soil was collected and gone through the hydrometer test, using a 1000-ml measuring cylinder and sodium silicate $\left(\mathrm{Na}_{2} \mathrm{SiO}_{3}\right)$ as a dispersing agent. The test was performed based on the British Standard 377: Part 1990:9.6.

\section{Grain-size analysis from empirical formulae}

To identify the hydraulic conductivity from grain-size analysis, the investigation was heavily based on empirical equations that depended largely on the parameter of diameter of sediment grains and other parameters such as the viscosity of water, porosity and sorting coefficient. A number of researchers (Kozeny 1927; Uma et al. 1989; Vukovic and Soro 1992; Kasenow 2002; Carrier 2003; Cheong et al. 2008; Eggleston and Rojstaczer 2001; Rosas et al. 2014) have all attempted to establish the correlations between these parameters which resulted in various estimations of hydraulic conductivity from the grain-size analysis. Such equations and their range of application are summarised in Table 1. The hydraulic conductivity $(K)$ can be estimated by analysing the particle size of the sediment of interest, using empirical equations relating to seize property of the sediment. In the literature written by Vukovic and Soro (1992), several empirical methods from former studies were summarised, and a universal, general formula is deduced as follows:

$K=\frac{g}{v} \cdot C \cdot f(n) d_{\mathrm{e}}^{2}$

where $K=$ hydraulic conductivity; $g=$ acceleration due to gravity; $v=$ kinematic viscosity; $C=$ sorting coefficient; $f(n)=$ porosity function and $d_{\mathrm{e}}=$ effective grain diameter. The kinematic viscosity $(v)$ is related to dynamic viscosity $(\mu)$ and the fluid (water) density $(\rho)$ as follows:

$v=\frac{\mu}{\rho}$

The values of $C, f(n)$ and $d_{\mathrm{e}}$ are dependent on the different methods used in the grain-size analysis. According to Vukovic and Soro (1992), porosity ( $n$ ) may be derived from the empirical relationship with the coefficient of grain uniformity $(U)$ as follows:

$n=0.255(1+0.83)^{U}$ 


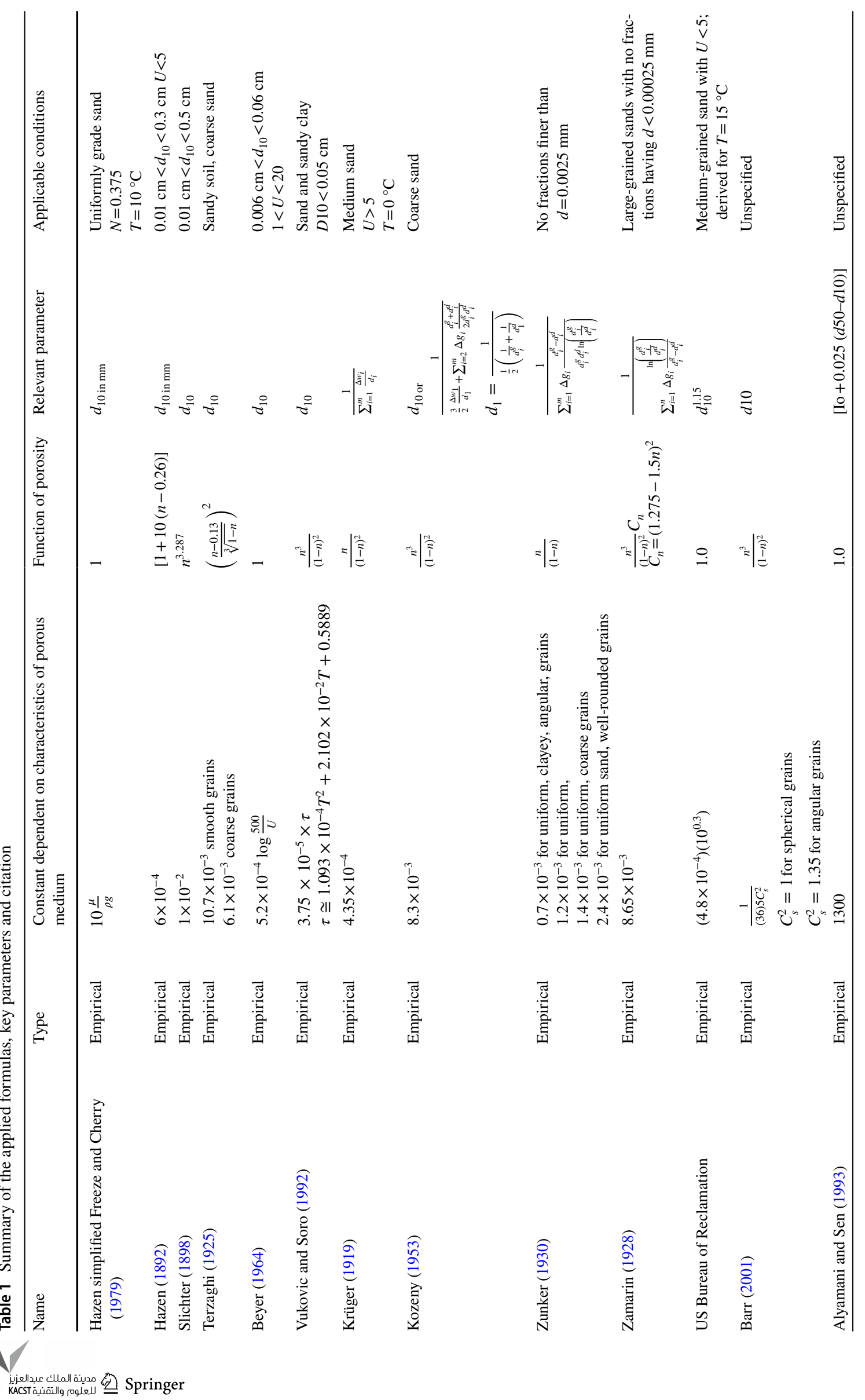




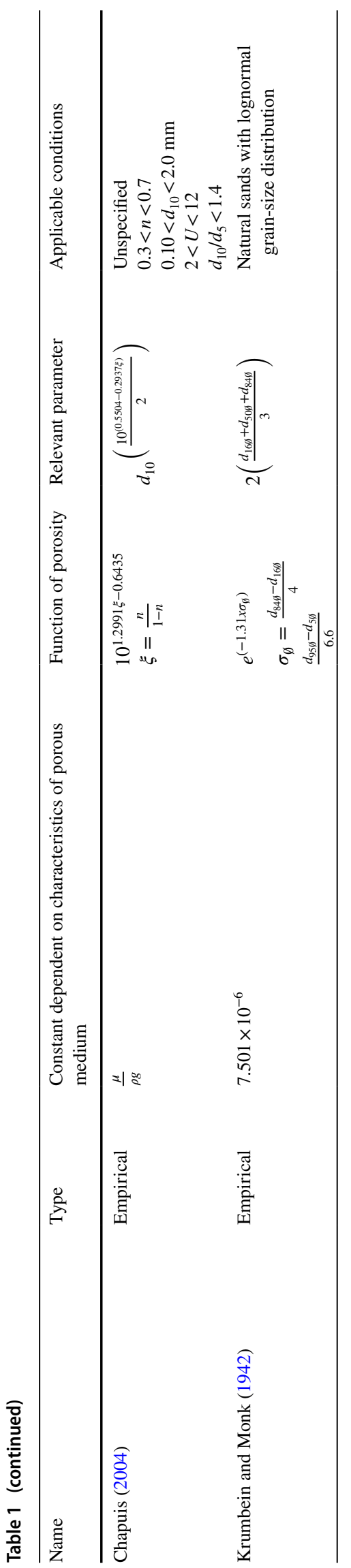

where $U$ is the coefficient of grain uniformity and is given by:

$U=\frac{U_{60}}{U_{10}}$

In this study, the empirical methods [Hazen, Hazen $K$ $(\mathrm{cm} / \mathrm{s})=d_{10}(\mathrm{~mm})$, Slichter, Beyer, Terzaghi, Sauerbrei, Kruger, Kozeny-Carmen, Zamarin, Zunker USBR, Barr, Alyamani and Sen, Chapuis, and Krumbein and Monk] were used to determine $K$. The summary of these formulas and their application domain of sediment particle size is outlined in Table 1. The results by which hydraulic conductivities were calculated using the twelve empirical formulae and symbols as explained are presented in Table 2. Since the kinematic coefficient of viscosity is also necessary for the estimation of hydraulic conductivity, a value of $0.0722 \mathrm{~m}^{2} /$ day derived for a water temperature of $28{ }^{\circ} \mathrm{C}$ was used in this study.

\section{Riverbed sediment sampling}

The riverbed drilling was carried out using boring machine and accessories that floated in the river by using approximately 16 square metres of pontoon. In order to avoid borehole walls from collapsing, steel casting HW size $114.3 \mathrm{~mm}$ O.D. and NW $88.9 \mathrm{~mm}$ O.D. was used. The boreholes were then washed by circulating water from drilling pump. Afterwards, the necessary soil samples were collected for visual examination and laboratory testing. In addition, the drilling process had been carried out in accordance with good practice as described in ASTM D2113-14 (2014). The drilling focused on obtaining the core samples by penetrating the full depth of the strata. In order to get to that point, the non-retractable core barrels with $54.0 \mathrm{~mm}(N$ size $)$ of core diameter were operated. In comparison, the sediment sampling method utilised a special sand bit of $30 \mathrm{~mm}$ diameter and $0.5 \mathrm{~m}$ length, connected to steel rods that used for drilling. The bit was driven into soil manually at certain depth through the river water level of $4.5 \mathrm{~m}$. The method is also suitable to be conducted on self-supporting ground without hard obstructions or gravel-sized to boulder-sized particles. Subsequently, the sandy material trapped inside the bit was taken out from the drilled hole and kept in poly bags before sending in for laboratory test. As for this study, the standpipe method has been chosen to determine the riverbed permeability of Muda River Basin as it can be performed directly in river and produces adequate outcomes to measure in situ aquifer. Furthermore, the method is suitable to observe the key parameters involved in evaluating riverbank filtration in this study which are the riverbed permeability, the aquifer transmissivity and the hydrogeological setting. The method was firstly conducted by operating the in situ standpipe 
test at the location. Two standpipes of uPVC material with $75 \mathrm{~mm}$ and $100 \mathrm{~mm}(D)$ diameter were carefully inserted into the river streambed to minimise any disturbance on the hyporheic layer. The standpipe of $117 \mathrm{~mm}$ depth $\left(L_{\mathrm{v}}\right)$ was then vertically inserted into the riverbed. Streambed sediment of $150 \mathrm{~mm}$ height $\left(L_{\mathrm{v}}\right)$ was expected to fill the bottom part of the pipes. The pipe was in vertical position, while the river water is pour into the standpipes. The changes by which the levels drop to the surface water level $\left(h_{1}\right.$ and $\left.h_{2}\right)$ and the time taken $\left(t_{1}\right.$ and $\left.t_{2}\right)$ each drop were measured, respectively.

\section{In situ permeability test}

As described by Chen $(2000,2004)$, the falling head standpipe permeability test was conducted to measure streambeds $K$. A transparent polycarbonate tube, $147 \mathrm{~cm}$ in length and $5.1 \mathrm{~cm}$ in diameter, was pressed vertically into the streambed sediments to a depth of around $50-70 \mathrm{~cm}$ below the river surface. Then, a column of unconsolidated river sediments was collected in the tube. This thin wall, which was about one millimetre thick, was very functional to minimise the compaction of streambed sediments during penetration. Afterwards, water was added from top opening of the tube and hydraulic head measurements were collected in a time period. Finally, the streambed $K$ values for the tested locations are calculated using the equation of Hvorslev (1951):
$K=\frac{\frac{\pi D}{11 m}+L_{\mathrm{v}}}{\left(t_{2}-t_{1}\right)} \ln \left(\frac{h_{1}}{h_{2}}\right)$

where $L_{\mathrm{v}}$ is the length of sediment core in the tube; $h_{1}$ and $h_{2}$ are hydraulic head inside the tube measured at times $t_{1}$ and $t_{2}$, respectively, $D$ is the interior diameter of the tube, and $m \sqrt{\frac{K_{\mathrm{h}}}{K_{\mathrm{v}}}} \cdot K_{\mathrm{h}}$ is the horizontal hydraulic conductivity of the streambed sediment around the base of the sediment core (Fig. 3).

\section{Hydraulic parameters by pumping tests}

To establish the hydraulic parameters of the alluvial layers, four pumping tests (TW1-TW4) were conducted. The pumping rates were fixed constant for every different well with a pumping duration shown in Table 3 . The Papadopulos-Cooper method and the Theis method were chosen to identify $S$ and $T$ as their methodology fits the water-level data and field hydrogeology the most. The Papadopulos-Cooper method which fits the corrected drawdown on the pumping well data and the Theis method with corrected drawdown on the observation well data were utilised to analyse the outcomes of the pump tests. Based on the observation of the data at for TW1-TW4 relative to each pumping well, the values of $T$ and $S$ were then deduced. Value of $K$

Table 2 List of symbols

\begin{tabular}{ll}
\hline Symbol & Denotation \\
\hline$N$ & Constant dependent on characteristics of the porous medium \\
$\varphi(n)$ & Function of porosity \\
$T$ & Water temperature \\
$g$ & Acceleration of gravity \\
$\rho$ & Volumetric mass density \\
$\mu$ & Dynamic viscosity \\
$\tau$ & Ratio of a circle's circumference to its radius, \\
$n$ & Porosity as fraction of aquifer volume \\
$d_{i}^{g}$ & The maximum grain diameter in fraction $i$ \\
$d_{i}^{d}$ & The minimum grain diameter in fraction $i$ \\
$d_{10}$ & Grain size (cm) corresponding to $10 \%$ by weight passing through the sieves \\
$d_{20}$ & Grain size (cm) corresponding to $20 \%$ by weight passing through the sieves \\
$d_{50}$ & Grain size (cm) corresponding to $50 \%$ by weight passing through the sieves \\
$U=\frac{d_{60}}{d_{10}}$ & Coefficient of grain uniformity \\
$\Delta g_{i}$ & Weight of the $i$ th fraction \\
$d_{60}$ & Grain size (cm) corresponding to $60 \%$ by weight passing through the sieves \\
$\Delta w_{l}$ & Fraction of total weight of sample with fraction identifies ' $i$ \\
$d_{i}$ & Mean grain diameter of the fraction i \\
$d_{i ø}$ & Mean grain diameter of the fraction $I$ in phi units \\
$l_{o}$ & $x$-intercept (grain size) of a per cent grain retention curve plotted on arith- \\
& metic axes and focussing on data below $50 \%$ retained \\
\hline &
\end{tabular}


was calculated by dividing $T$ by the thickness of the sand/ gravel layer. Based on the calculations, it was discovered that to consider a constant head boundary with a partial penetration to the aquifer was more realistic than the previously mentioned methods for interpreting the pumping test. The solution proposed by Hunt's (1999) that took into account the streambed clogging and partial stream penetration was more general as compared to Hantush's (1965) approach, which considered a fully penetrating streambed lined with semi-pervious material. It was also broader than the solutions of Theis (1941) and Glover and Balmer (1954), which assumed a fully penetrated stream was adjacent to a homogeneous aquifer. The model of Fox et al. (2002) was perceived to have more accuracy than Hunt's (1999) solution it took into account the width of the stream. Fox et al. revealed that the deviations in the predicted drawdown between the two models may range between 10 and $20 \%$ when the ratio of the distance between the stream and the aquifer to the stream was greater than $25 \mathrm{~m}$ with a dimensionless time at $100 \mathrm{~m}$. Additionally, a model proposed by Butler et al. (2001) which accounted for a partially penetrating stream with a finite width and an aquifer of limited lateral extent can also be considered. However, all numerous researchers

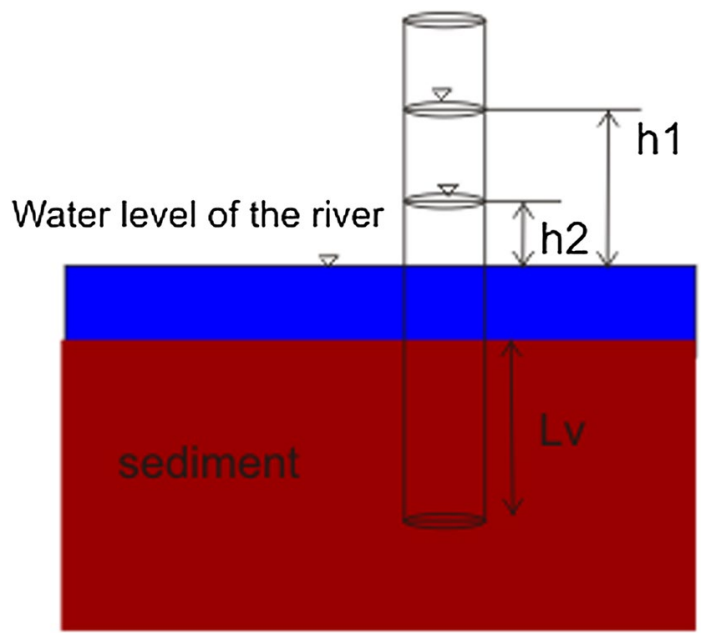

Fig. 3 Schematic diagrams showing an in situ permeameter test to determine streambed $K$ mentioned the solutions that already presumed the existence of an isotropic aquifer, which is not appropriate for this study area since the aquifer system is composed of six layers (upper fine sand, medium sand, lower fine sand and sand/gravel layers). Therefore, this study opted to operate the pumping test, which can account for a complex field site. In the field, the hydraulic conductivity and other soil properties can be determined by several methods that produce minimal disturbance to the soil and hence may provide more accurate measurements.

\section{Results and discussion}

\section{$K_{\mathrm{g}}$ and $K_{\mathrm{gs}}$ values using the empirical formulas}

In Table 4, the calculated $K_{\mathrm{g}}$ and $K_{\mathrm{gs}}$ values from the results of the grain-size analysis are presented. Values identified from twelve formulas are plotted in graph plots, indicating the layer 1 to layer 6 for riverbank sediments and streambed sediments. The $K$ value from grain-size analysis for $K_{\mathrm{g}}$ (grain size) and $K_{\mathrm{gs}}$ (hydraulic conductivity streambeds) was identified from the twelve (12) empirical grain-size methods with depth until $30 \mathrm{~m}$ with 144 samples and streambed with 21 samples up to until $9 \mathrm{~m}$. The 12 empirical grain sizes are listed as Hazen, Hazen (Simplified (Freeze and Cherry 1979), Slichter, Terzaghi, Beyer, Sauerbrei, Kruger, Kozeny-Carmen, Zunker, Zamarin, USBR, Barr, Alyamani and Sen, Chapuis and Krumbein and Monk. The estimated hydraulic conductivities for the samples of both riverbank sediment and streambed sediment (Fig. 4), which employed the 12 methods without any statistical adjustments and a measured values and geometry mean of $K_{\mathrm{g}}$ and $K_{\mathrm{gg}}$, are all presented in Table 4. In Table 5, the range and average values of $K_{\mathrm{g}}$ and $K_{\mathrm{gs}}$ identified by the 12 empirical formulas are summarised. The key properties of the grain-size distribution, including $d 10, d 17, d 20, d 50, d 60$, hydraulic conductivity, porosity, and mean $K_{\mathrm{g}}$, for all samples are also listed in Table 4. In all the analysed samples (Table 5), it was discovered that layers 1-6 exhibited the highest values of hydraulic conductivities which were obtained by the Hazen, Slichter, Terzaghi, Beyer, Sauerbrei, Kruger, Kozeny-Carmen,

Table 3 Pumping rate for 3 days for test wells at the study area

\begin{tabular}{lllllllc}
\hline Well Id & X & Y & Elevation & Pumping start date & Pumping end date & $\begin{array}{c}\text { Pumping rate }\left(\mathrm{m}^{3} / \mathrm{h}\right) \\
\begin{array}{c}\text { Pumping } \\
\text { rate }\left(\mathrm{m}^{3} /\right. \\
\text { day })\end{array}\end{array}$ \\
\hline TW 01 & $278,133.7950$ & $616,761.6355$ & 4.9233 & $10 / 10 / 2014$ & $13 / 10 / 2014$ & -43.92 & -1054.08 \\
TW 02 & $278,427.1747$ & $616,179.0141$ & 5.4211 & $14 / 10 / 2014$ & $17 / 10 / 2014$ & -51.609 & -1238.62 \\
TW 03 & $284,943.8415$ & $614,169.9044$ & 10.9730 & $11 / 8 / 2015$ & $13 / 8 / 2015$ & -36.961 & -887.064 \\
TW 04 & $280,623.4251$ & $615,753.4388$ & 9.4880 & $15 / 8 / 2015$ & $17 / 8 / 2015$ & -60.056 & -1441.34 \\
\hline
\end{tabular}


Zunker and Zamarin, USBR, Barr, Alyamani and Sen, Chapuis, Krumbein and Monk method. Interestingly, the Hazen, Terzaghi, Beyer, Sauerbrei, Slichter, Barr, USBR, Krumbein and Monk methods provided the lowest estimations of $K$, and this group of data were statistically different from all of the others (with significant difference). The Beyer and Hazen and Sauerbrei and USBR, Barr, Alyamani, and Sen, Chapuis and Krumbein and Monk methods also gave very similar values as the outcomes. These values differed greatly depending on the individual methods. Furthermore, the Kozeny method yielded the highest values of hydraulic conductivities for layer 2 and layer 3 , and the $K_{\mathrm{g}}$ values calculated by the Slichter, Terzaghi, Barr and Chapuis methods were lower than those derived from the other empirical grain-size methods. This is not unusual as some authors also agreed that the methods of Hazen, Terzaghi and Beyer tend to produce very similar results. Interestingly, Song et al. (2009) discovered that the lowest values were actually produced by the USBR method. Chua et al. (2007) observed that $K_{\mathrm{g}}$ estimated from the Hazen and Beyer methods agreed reasonably well. Moreover, the streambed sediments consisted mostly of gravel and some sand in the Muda River. There were more than $70 \%$ of weight percentages of the sediments observed in this investigation fell in the category of sand with ranging between 0.05 and $2 \mathrm{~mm}$ of particle diameter. Most of the sediment samples are in categories of silt and clay (particle diameter $<0.06 \mathrm{~mm}$ ) representing less than $7 \%$ of the total weight. Based on these grain-size distribution plot and curves, the results indicated that the streambed of sediment RB2 was coarser than those in sediments RB1 and RB3 (Table 6). According to the domain of applicability of the empirical methods (Table 1), sediment samples from RB2 were not applicable to undergo Sauerbrei method due to the theories and fact that the grain diameters of $d 17$ were greater than $0.05 \mathrm{~mm}$. The $d 10, d 17, d 20, d 50$ and $d 60$ and the porosity of the grain size of sediments for the three locations of sample borehole are listed in Table 4. It should also be considered that geochemical, biological activities and gas produced by redox process exchange greatly affected the $K_{\mathrm{v}}$ values in a streambed of sediments, as mentioned by Song et al. (2007). The invertebrate bioturbation and gas bubble ebullition (mainly from bacterial and invertebrate activities) could loosen the sediments, resulting in an increase in streambed $K_{\mathrm{v}}$. Therefore, it cannot be ignored that biological activities may also have partially contributed to the greater $K_{\mathrm{v}}$ of streambed. However, this effect of biological activities may have been restricted only to the thick of top layer of streambed as the number of invertebrates decreased dramatically in lower layers.

\section{$K$ value from pumping test}

As previously described, the pumping tests were conducted on four pumping wells (TW1-TW4) and were monitoring wells (MW8, MW3, MW17 and MW22) as to establish the value of hydraulic conductivity parameters of the alluvial layers. The pumping rates were put constant for different wells by using a pumping period and monitoring wells, as shown in Table 3. In order to determine the value of $T$ and $S$, the methods chosen were the ones that deemed as the best fit the field hydrogeology and water-level data. Next, to evaluate the pump tests, the Theis and Theis recovery methods with corrected drawdown on the observation well data were applied. Values of $T$ and $S$ were determined from the observed data at wells TW1-TW4 relative to each pumping well. The value of $T$ ranged from $5.70 \times 10^{1}$ to $1.22 \times 10^{3} \mathrm{~m}^{2} /$ day (Table 7), while $S$ ranged from $1.00 \times 10^{-7}$ to $3.18 \times 10^{-7}$. $K$ value was calculated by dividing $T$ by the thickness of the sand/gravel layer at the pumping wells. The calculated estimates for $K$ ranged from $1.48 \times 10^{1}$ to $8.09 \times 10^{1} \mathrm{~m} /$ day.

\section{Measurement of permeability from falling head permeability tests in boreholes}

As to adhere the procedures provided in BS 5930, the in situ falling head permeability tests were conducted at regular intervals in eleven boreholes down to a depth of $30 \mathrm{~m}$ and four of boreholes near riverbank and riverbed sediment to a depth of $8 \mathrm{~m}$. The test was performed by filling the casing with water which was firstly seeped into the soil. The water depth inside the casing was measured at specific time intervals from the start of the test. These measurements were recorded until a sufficient number of readings were obtained or when the rate of drop was very small, as to accurately determine the permeability. The field falling head tests were preferred because they provided more reliable data compared to laboratory tests as this method avoided soil disturbance and managed to test a relatively larger volume of soil. In comparison with pumping tests, the falling head test was only able to measure the permeability of a limited volume of soil, but it produced a more detailed profile of the permeability versus depth. Figure 5 shows the measured values of permeability versus depth at three boreholes. Based on the outcomes, it can be observed that the measured permeability varied between $5.13 \times 10^{-4}$ and $8.60 \times 10^{-6} \mathrm{~m} / \mathrm{s}$ with an average value of approximately $8.73 \times 10^{-5} \mathrm{~m} / \mathrm{s}$. Most of the values lied between $5 \times 10^{-7}$ and $1 \times 10^{-4} \mathrm{~m} / \mathrm{s}$, which were within the typical range of permeability of very fine sands, medium sand and gravelly coarse sand. As for the riverbed and riverbank sediments, most of the values lie between $1.26 \times 10^{-5}$ and $4.25 \times 10^{-7} \mathrm{~m} / \mathrm{s}$ which fell within the typical range of permeability of medium sand and gravelly coarse 
Fig. 4 Estimated hydraulic conductivity using the empirical methods for six layers for 22 boreholes (symbols) with geometric mean (blue line). (a) Layer 1, (b) Layer 2, (c) Layer 3, (d) Layer 4, (e) Layer 5 and (f) Layer 6

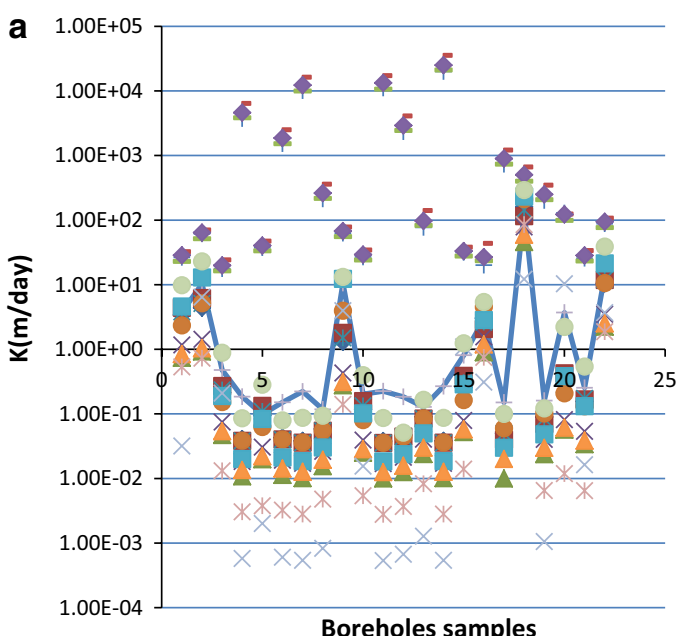

Boreholes samples
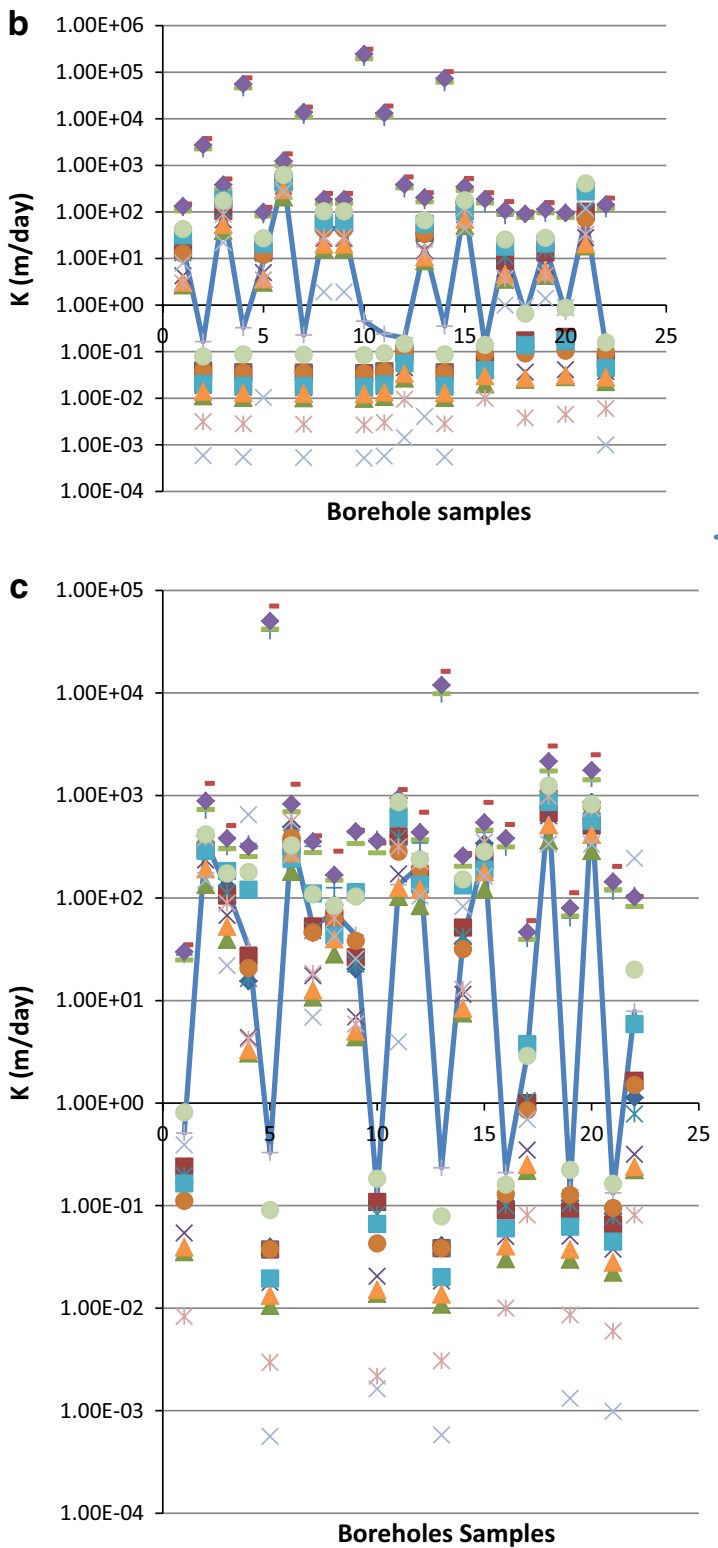

- Hazen

Hazen $\mathrm{K}(\mathrm{cm} / \mathrm{s})=\mathrm{d} 10(\mathrm{~mm})$

$\Delta$ Slichter

$\times$ Terzaghi

* Beyer

- Sauerbrei

+ Kruger

- Kozeny-Carmen

- Zunker

- Zamarin

USBR

$\triangle$ Barr

Alyamani and Sen

* Chapuis

- Krumbein and Monk

+ geometric mean

- Hazen

Hazen $\mathrm{K}(\mathrm{cm} / \mathrm{s})=\mathrm{d} 10(\mathrm{~mm})$

- Slichter

$\times$ Terzaghi

* Beyer

- Sauerbrei

+ Kruger

- Kozeny-Carmen

- Zunker

- Zamarin

- USBR

$\triangle$ Barr

Alyamani and Sen

* Chapuis

Krumbein and Monk

- geometric mean

$\rightarrow$ Hazen

- Hazen $\mathrm{K}(\mathrm{cm} / \mathrm{s})=\mathrm{d} 10(\mathrm{~mm})$

A Slichter

$\times$ Terzaghi

* Beyer

- Sauerbrei

+ Kruger

- Kozeny-Carmen

- Zunker

- Zamarin

- USBR

$\triangle$ Barr

$\times$ Alyamani and Sen

* Chapuis

Krumbein and Monk

- geometric mean 
Fig. 4 (continued)
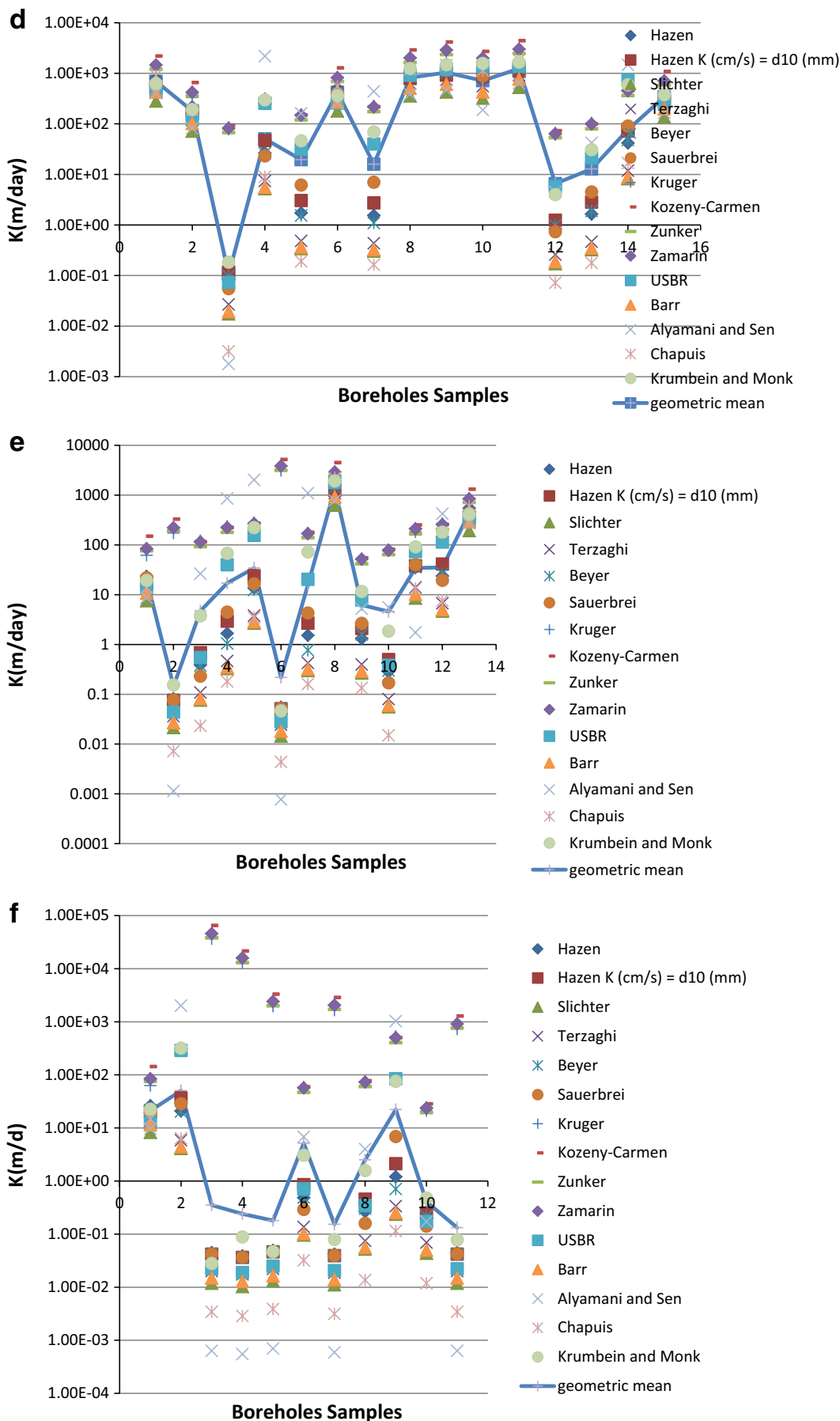

\begin{tabular}{l} 
Hazen \\
- Hazen K $(\mathrm{cm} / \mathrm{s})=\mathrm{d} 10(\mathrm{~mm})$ \\
$\times$ Terzaghi \\
* Beyer \\
- Sauerbrei \\
+ Kruger \\
- Kozeny-Carmen \\
- Zunker \\
Zamarin \\
- USBR \\
$\triangle$ Barr \\
$\times$ Alyamani and Sen \\
* Chapuis \\
Krumbein and Monk \\
\hline
\end{tabular}

sand (Table 8). Comparison between the results of the falling head permeability test and the values obtained from pumping tests was then made. Both tests exhibited similar trends with the measured permeability decreasing along with depth. Pumping test exhibited a coefficient of permeability that was slightly higher than the values obtained from the falling head test. On the other hand, the permeability values obtained from pumping tests compare well with the values measured from the falling head test. This highlighted the fact that the permeability of the soil depends on a good aquifer capacity. According to the results of the soil's permeability, it is reasonable to classify this soil as gravel and medium sand. Based on the observations made, it could be concluded that the aquifer in the study area has indeed shown a potential for riverbank filtration ( $\mathrm{RBF})$, and there are bright chances to increase the water quality and water quantity of the studied area.

A comparative analysis of $K_{\mathrm{g}}$ values was performed to gain intelligence on the spatial variation of streambed $K_{\mathrm{gs}}$. The hydraulic conductivity of the environment sediment 


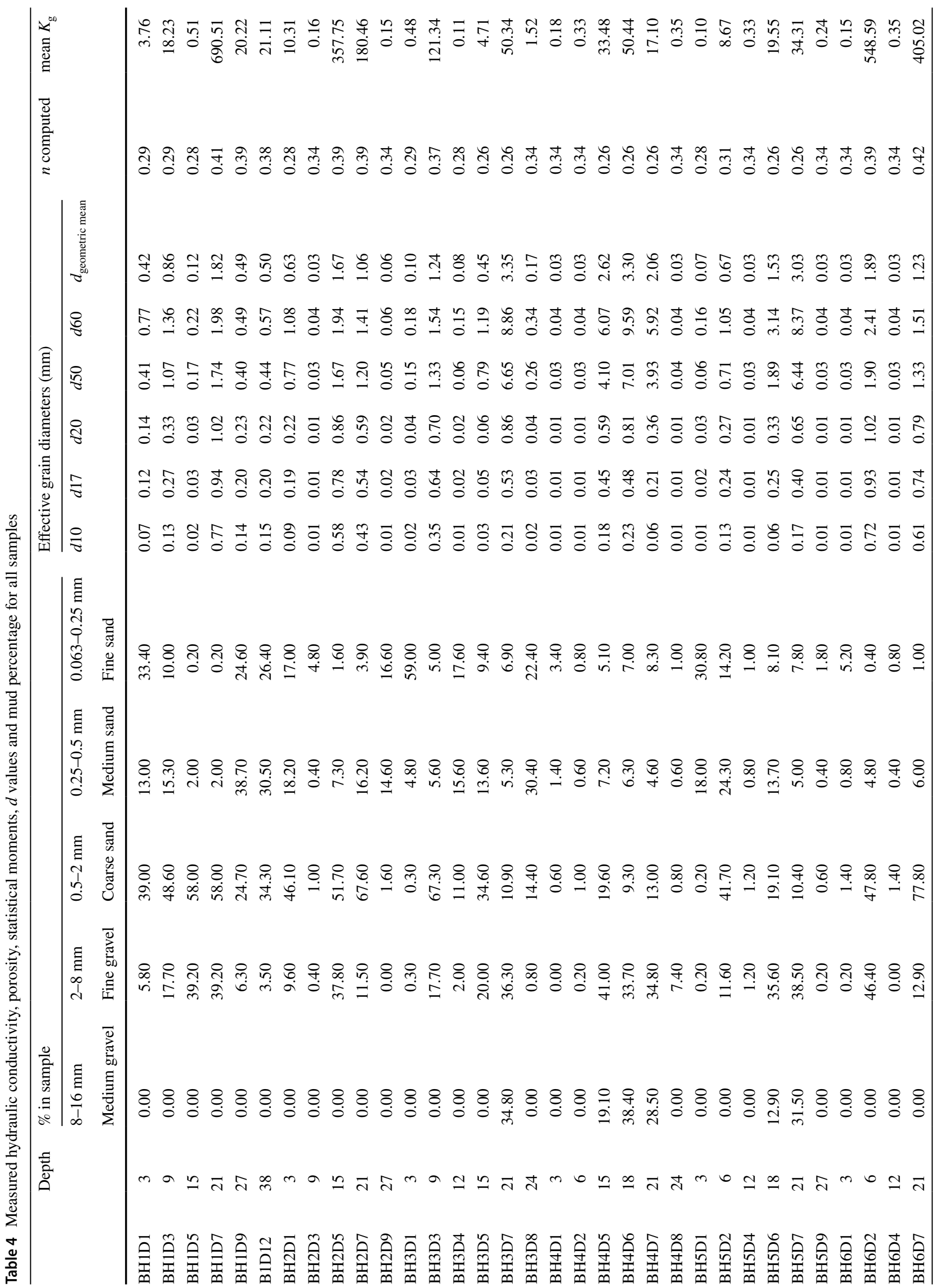




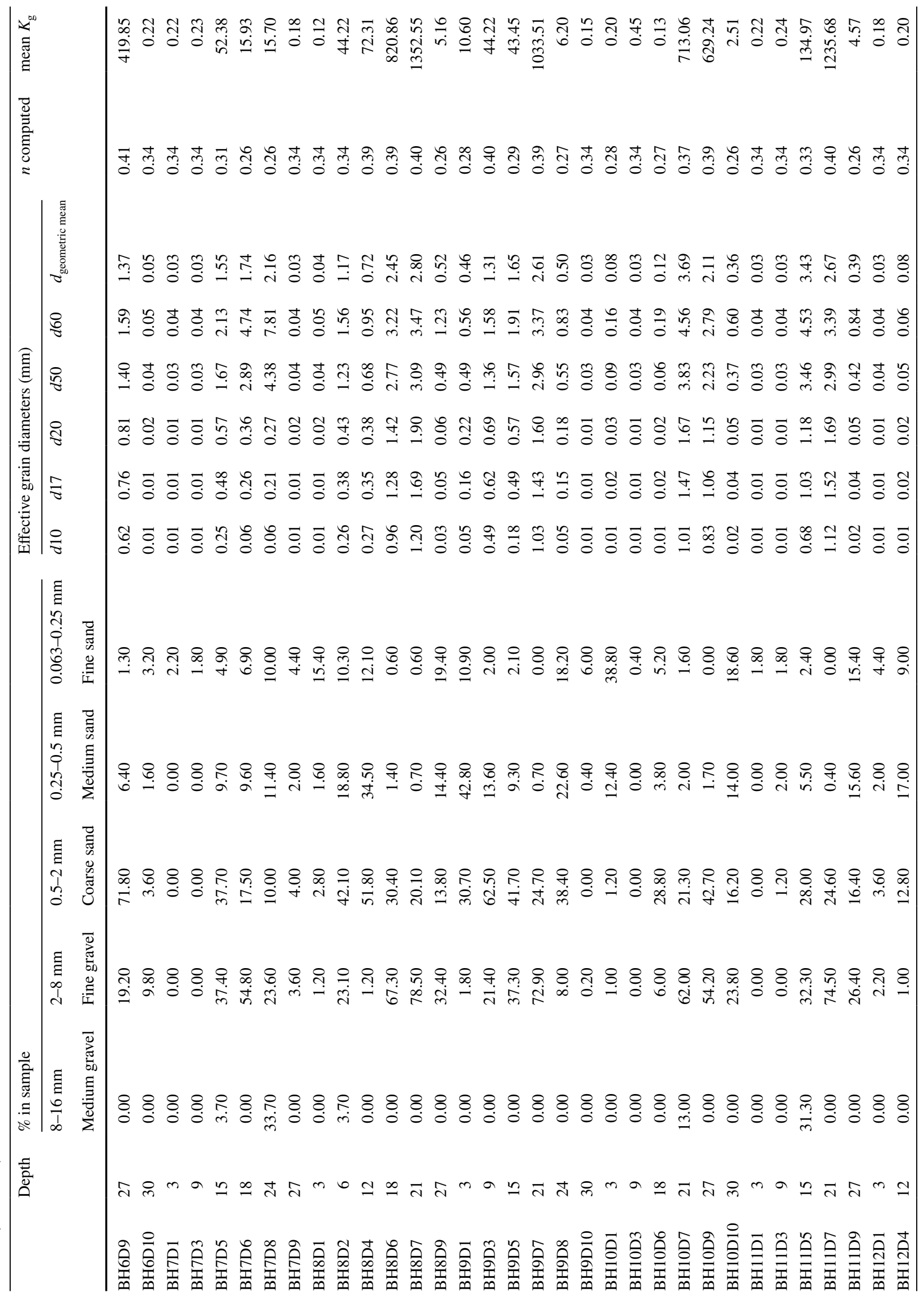




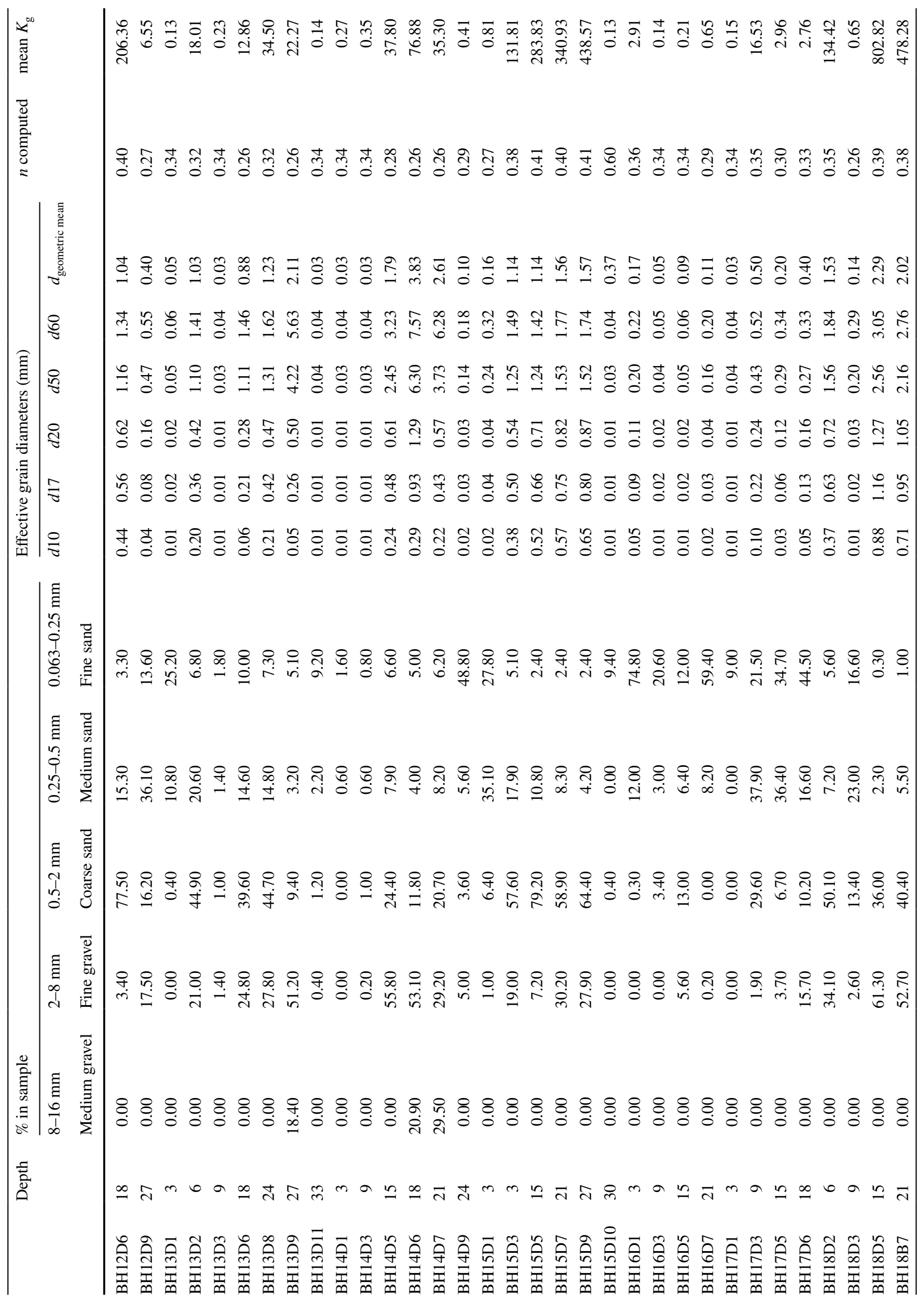




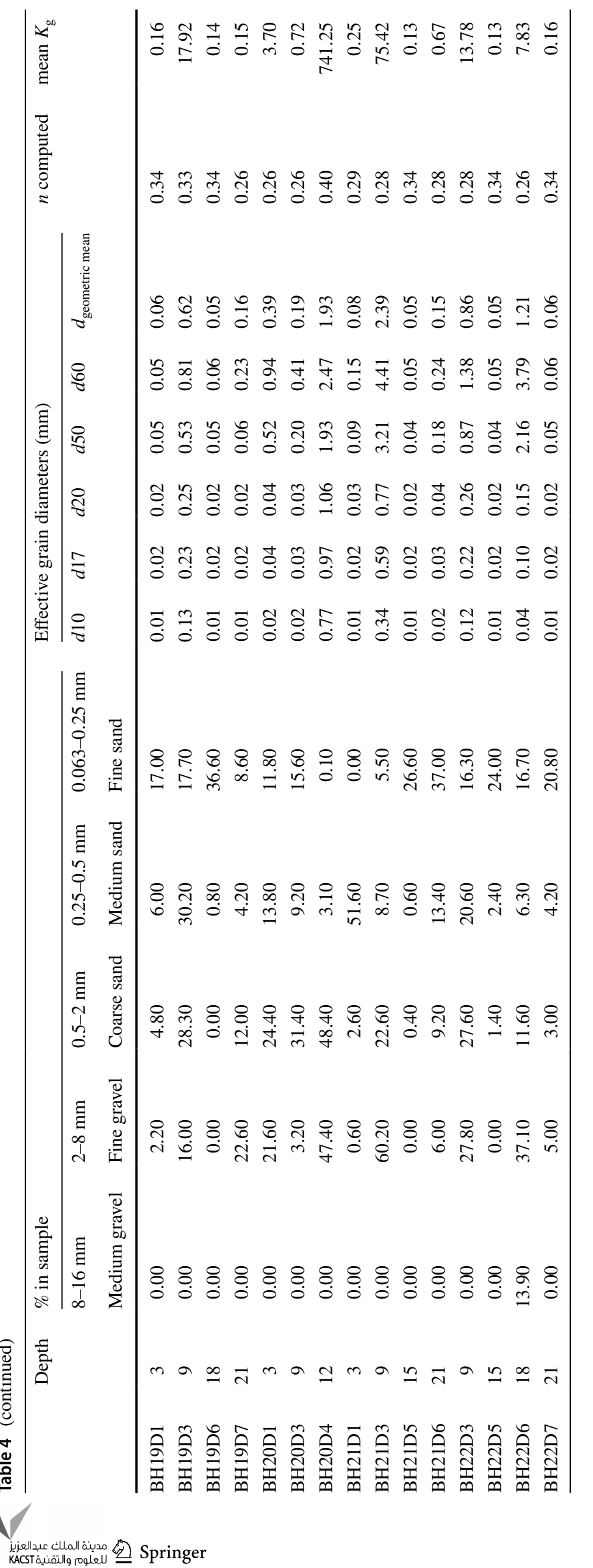


Table 5 Values of geometry mean of $K v$ (in $\mathrm{m} / \mathrm{s}$ ) for methods used by grain-size analyses for six layers in Lower Muda Basin

\begin{tabular}{lrrrrrr}
\hline Method & Layer 1 (m/day) & \multicolumn{1}{c}{ Layer 2 } & Layer 3 & Layer 4 & Layer 5 & Layer 6 \\
\hline Hazen & 8.42 & 55.08 & 190.71 & 364.18 & 188.37 & 4.49 \\
Hazen $K(\mathrm{~cm} / \mathrm{s})=d 10(\mathrm{~mm})$ & 6.51 & 44.79 & 133.35 & 263.15 & 133.59 & 5.51 \\
Slichter & 2.32 & 16.72 & 62.07 & 120.44 & 64.89 & 1.17 \\
Terzaghi & 3.95 & 28.79 & 107.90 & 209.93 & 113.41 & 1.90 \\
Beyer & 7.71 & 48.00 & 158.44 & 297.47 & 150.88 & 3.99 \\
Sauerbrei & 10.86 & 46.63 & 166.89 & 312.97 & 178.82 & 5.06 \\
Kruger & 2315.94 & $15,287.42$ & 2678.15 & 665.02 & 598.07 & 4984.30 \\
Kozeny-Carmen & 3876.01 & $24,246.99$ & 4588.60 & 1111.44 & 962.63 & 8627.88 \\
Zunker & 2337.85 & $14,874.59$ & 2737.50 & 644.55 & 587.59 & 5153.38 \\
Zamarin & 2845.10 & $18,454.65$ & 3308.32 & 791.76 & 711.55 & 6191.28 \\
USBR & 13.03 & 57.07 & 163.70 & 359.99 & 193.49 & 35.21 \\
Barr & 2.99 & 22.81 & 88.08 & 171.99 & 95.07 & 1.49 \\
Alyamani and Sen & 1.74 & 21.57 & 110.24 & 335.92 & 421.96 & 277.94 \\
Chapuis & 4.07 & 43.73 & 170.90 & 390.24 & 218.66 & 1.94 \\
Krumbein and Monk & 17.66 & 80.93 & 228.67 & 445.60 & 230.50 & 38.42 \\
\hline
\end{tabular}

Table 6 Mean of $K_{\mathrm{g}}$ value from empirical data for streambed (right, left and middle of river) until $8 \mathrm{~m}$ depth

\begin{tabular}{|c|c|c|c|c|c|c|c|c|c|c|c|c|}
\hline \multirow[t]{2}{*}{ Depth (m) } & \multirow[t]{2}{*}{$2-8 \mathrm{~mm}$} & \multirow[t]{2}{*}{$0.5-2 \mathrm{~mm}$} & \multirow[t]{2}{*}{$0.25-0.5 \mathrm{~mm}$} & \multirow[t]{2}{*}{$0.063-0.25 \mathrm{~mm}$} & \multicolumn{6}{|c|}{ Effective grain diameters (mm) } & \multirow[t]{2}{*}{$n$} & \multirow[t]{2}{*}{ mean $K_{\mathrm{g}}$} \\
\hline & & & & & $d 10$ & $d 17$ & $d 20$ & $d 50$ & $d 60$ & $d_{\text {geometric mean }}$ & & \\
\hline \multicolumn{13}{|l|}{ RB1 } \\
\hline 4 & 9.12 & 17.71 & 14.80 & 54.19 & 0.08 & 0.11 & 0.12 & 0.22 & 0.32 & 0.31 & 0.38 & 7.56 \\
\hline 5 & 56.59 & 31.55 & 7.04 & 3.97 & 0.50 & 0.88 & 1.05 & 2.39 & 2.98 & 2.03 & 0.34 & 128.47 \\
\hline 6 & 12.80 & 53.91 & 18.49 & 13.67 & 0.21 & 0.33 & 0.37 & 1.10 & 1.36 & 0.88 & 0.33 & 25.58 \\
\hline 7 & 4.88 & 68.72 & 13.06 & 10.77 & 0.23 & 0.41 & 0.47 & 1.11 & 1.31 & 0.91 & 0.34 & 44.19 \\
\hline 8 & 13.93 & 46.20 & 15.32 & 17.46 & 0.10 & 0.20 & 0.24 & 0.86 & 1.11 & 0.68 & 0.29 & 12.41 \\
\hline \multicolumn{13}{|l|}{ RB2 } \\
\hline 4 & 42.220 & 37.950 & 9.660 & 8.850 & 0.295 & 0.496 & 0.606 & 1.689 & 2.132 & 1.414 & 0.32 & 54.77 \\
\hline 5 & 12.450 & 53.170 & 20.710 & 8.010 & 0.212 & 0.353 & 0.402 & 1.035 & 1.302 & 0.874 & 0.34 & 39.88 \\
\hline 6 & 13.250 & 41.600 & 18.750 & 23.340 & 0.110 & 0.163 & 0.197 & 0.744 & 1.042 & 0.598 & 0.30 & 9.8 \\
\hline 7 & 17.240 & 59.710 & 11.620 & 8.170 & 0.265 & 0.455 & 0.527 & 1.271 & 1.493 & 1.078 & 0.34 & 64.03 \\
\hline 8 & 38.560 & 37.690 & 12.070 & 11.450 & 0.264 & 0.420 & 0.499 & 1.613 & 1.951 & 1.368 & 0.32 & 49.92 \\
\hline \multicolumn{13}{|l|}{ RB3 } \\
\hline 4 & 44.050 & 25.640 & 15.350 & 13.080 & 0.194 & 0.331 & 0.378 & 1.696 & 2.306 & 1.347 & 0.28 & 32.25 \\
\hline 5 & 46.040 & 33.270 & 9.350 & 10.330 & 0.249 & 0.447 & 0.571 & 1.838 & 2.313 & 1.471 & 0.30 & 52.3 \\
\hline 6 & 35.250 & 33.570 & 14.960 & 14.070 & 0.180 & 0.312 & 0.359 & 1.427 & 1.815 & 1.116 & 0.29 & 29.11 \\
\hline 7 & 8.840 & 59.480 & 17.990 & 10.110 & 0.212 & 0.375 & 0.436 & 1.080 & 1.316 & 0.888 & 0.34 & 35.67 \\
\hline 8 & 9.280 & 44.400 & 18.250 & 23.230 & 0.102 & 0.157 & 0.196 & 0.707 & 0.997 & 0.568 & 0.30 & 9.11 \\
\hline \multicolumn{13}{|l|}{ RVB1 } \\
\hline 3 & 14.000 & 22.200 & 22.400 & 32.000 & 0.069 & 0.136 & 0.160 & 0.381 & 0.528 & 0.449 & 0.32 & 3.24 \\
\hline 6 & 16.000 & 53.600 & 25.200 & 4.300 & 0.370 & 0.459 & 0.490 & 1.112 & 1.373 & 0.999 & 0.38 & 150.35 \\
\hline 9 & 45.300 & 49.800 & 4.000 & 0.500 & 0.743 & 0.940 & 1.024 & 1.868 & 2.353 & 1.888 & 0.40 & 671.52 \\
\hline \multicolumn{13}{|l|}{ RVB2 } \\
\hline 3 & 1.600 & 12.200 & 16.800 & 18.800 & 0.012 & 0.021 & 0.025 & 0.062 & 0.158 & 0.089 & 0.28 & 0.13 \\
\hline 6 & 0.200 & 1.200 & 0.600 & 1.600 & 0.007 & 0.011 & 0.013 & 0.033 & 0.039 & 0.027 & 0.34 & 0.31 \\
\hline 9 & 1.800 & 8.400 & 3.600 & 4.000 & 0.008 & 0.013 & 0.015 & 0.038 & 0.046 & 0.043 & 0.34 & 0.23 \\
\hline
\end{tabular}


Table 7 Results of transmissivity $(T)$, hydraulic conductivity $(K)$ and storativity $(S)$ from pumping test and observation wells

\begin{tabular}{|c|c|c|c|c|c|}
\hline Well & Type & Analysis & $T\left(\mathrm{~m}^{2} /\right.$ day $)$ & $K$ (m/day) & Storativity $(S)$ \\
\hline \multirow[t]{2}{*}{ TW1 } & \multirow[t]{2}{*}{ Pumping test } & Theis & $2.42 \times 10^{2}$ & $2.42 \times 10^{1}$ & \multirow[t]{2}{*}{$3.18 \times 10^{-7}$} \\
\hline & & Theis recovery & $3.30 \times 10^{2}$ & $3.30 \times 10^{1}$ & \\
\hline \multirow[t]{2}{*}{ MW8 } & \multirow[t]{2}{*}{ Observation well } & Theis & $2.44 \times 10^{2}$ & $2.44 \times 10^{1}$ & \multirow[t]{2}{*}{$1.17 \times 10^{-9}$} \\
\hline & & Theis recovery & $3.30 \times 10^{2}$ & $3.30 \times 10^{1}$ & \\
\hline \multirow[t]{2}{*}{ TW 2} & \multirow[t]{2}{*}{ Pumping test } & Theis & $1.22 \times 10^{3}$ & $4.86 \times 10^{1}$ & \multirow[t]{2}{*}{$1.00 \times 10^{-7}$} \\
\hline & & Theis recovery & $7.91 \times 10^{2}$ & $3.17 \times 10^{1}$ & \\
\hline \multirow[t]{2}{*}{ MW3 } & \multirow[t]{2}{*}{ Observation well } & Theis & $5.30 \times 10^{2}$ & $2.12 \times 10^{1}$ & \multirow[t]{2}{*}{$1.00 \times 10^{-7}$} \\
\hline & & Theis recovery & $7.73 \times 10^{2}$ & $3.09 \times 10^{1}$ & \\
\hline \multirow[t]{2}{*}{ TW3 } & \multirow[t]{2}{*}{ Pumping test } & Theis & $4.53 \times 10^{2}$ & $1.89 \times 10^{1}$ & \multirow[t]{2}{*}{$1.00 \times 10^{-7}$} \\
\hline & & Theis recovery & $3.54 \times 10^{2}$ & $1.48 \times 10^{1}$ & \\
\hline \multirow[t]{2}{*}{ MW17 } & \multirow[t]{2}{*}{ Observation well } & Theis & $7.47 \times 10^{2}$ & $3.11 \times 10^{1}$ & \multirow[t]{2}{*}{$1.00 \times 10^{-7}$} \\
\hline & & Theis recovery & $1.19 \times 10^{3}$ & $4.97 \times 10^{1}$ & \\
\hline \multirow[t]{2}{*}{ TW4 } & \multirow[t]{2}{*}{ Pumping test } & Theis & $1.20 \times 10^{3}$ & $5.01 \times 10^{1}$ & \multirow[t]{2}{*}{$1.00 \times 10^{-7}$} \\
\hline & & Theis recovery & $1.94 \times 10^{3}$ & $8.09 \times 10^{1}$ & \\
\hline \multirow[t]{2}{*}{ MW22 } & \multirow[t]{2}{*}{ Observation well } & Theis & $5.70 \times 10^{1}$ & $2.38 \times 10^{1}$ & \multirow[t]{2}{*}{$1.00 \times 10^{-7}$} \\
\hline & & Theis recovery & $5.75 \times 10^{2}$ & $2.40 \times 10^{1}$ & \\
\hline
\end{tabular}

Table 8 Field permeability test from falling head test versus depths for riverbed and riverbanks from observation wells

\begin{tabular}{lll}
\hline Name & Depth $(\mathrm{m})$ & Permeability test $(\mathrm{m} /$ day $)$ \\
\hline RB1 & 3.5 & $1.09 \mathrm{E}+00$ \\
& 7.5 & $1.88 \mathrm{E}-01$ \\
RB2 & 4 & $6.62 \mathrm{E}-01$ \\
& 8 & $1.55 \mathrm{E}-01$ \\
RB3 & 4 & $3.67 \mathrm{E}-02$ \\
& 8 & $6.83 \mathrm{E}-01$ \\
RVB1 & 9 & $2.85 \mathrm{E}-01$ \\
RVB2 & 9 & $2.51 \mathrm{E}-01$ \\
\hline Well name & Depth (m) & Permeability test (m/day) \\
\hline Observation wells & & \\
MW16 & 24 & $6.42 \mathrm{E}+00$ \\
MW17 & 20.3 & $3.97 \mathrm{E}+00$ \\
MW18 & 21.82 & $2.76 \mathrm{E}+00$ \\
MW19 & 21.52 & $8.64 \mathrm{E}+00$ \\
MW20 & 14.4 & $2.85 \mathrm{E}+00$ \\
MW21 & 19.4 & $2.64 \mathrm{E}+00$ \\
MW22 & 24.29 & $2.79 \mathrm{E}+00$ \\
MW7 & 27 & $7.43 \mathrm{E}-01$ \\
MW15 & 30 & $6.05 \mathrm{E}-01$ \\
MW5 & 27 & $4.43 \mathrm{E}+01$ \\
MW6 & 30 & $3.80 \mathrm{E}+00$ \\
\hline
\end{tabular}

largely controlled the geology of sediments and thus affected the overall hydraulic conductivity. However, these physical, biological and chemical clogging processes (post-depositional processes) may also had an impact on the alteration of the original $K_{\mathrm{v}}$ that then contributed to the variation of streambed $K_{\mathrm{v}}$ (Hancock 2002; Chen et al. 2013). In the channel sediments where the flow velocity is generally higher, a larger $K_{\mathrm{v}}$ value may be recorded, since fine-grained sediments could be washed away by higher flows and caused them to deposit again in the area with lower velocity (Chen 2005a, b). Meanwhile, silt/clay materials were discovered to accumulate primarily in the areas of high inflow with larger water depth (Packman and MacKay 2003), which may then leading to the smaller $K_{\mathrm{v}}$ in the middle of the river. Furthermore, in general, any area that is close to the erosional bank has higher possibility to reach higher value of $K_{\mathrm{v}}$ as compared to the depositional bank. Therefore, this contrasting distribution pattern in $K_{\mathrm{v}}$ across the stream was probably due to the infiltration of fine particles and the bend of the river channel. There was an interesting finding in the research conducted by Chen et al. (2013) by which they collected a sequence of cores from sediments below the top layer to a depth of about 10-15 $\mathrm{m}$ and identified the value of $K_{\mathrm{v}}$ for these cores. The research discovered that in the losing streams, $K_{\mathrm{v}}$ increased with the depth of the cores, while in the gaining streams, $K_{\mathrm{v}}$ decreased with the depth of the cores.

\section{Conclusion}

The identification of vertical riverbank and streambed hydraulic conductivity holds very essential significance in the analysis of river-aquifer interactions and riverbank filtration systems $(\mathrm{RBF})$. The grain-size analysis, pumping test and in situ falling head permeability tests were conducted to identify riverbank and streambed vertical hydraulic conductivity $(K)$ of six layers for riverbank with depths of $38 \mathrm{~m}$ and streambed to depths of $9 \mathrm{~m}$ of sediments at 22 test locations, 
Fig. 5 Estimated hydraulic conductivity using the empirical methods for streambeds (symbols) RVB1 (a), RVB2 (b) and RVB3 (c) with depth and geometric mean (blue line)

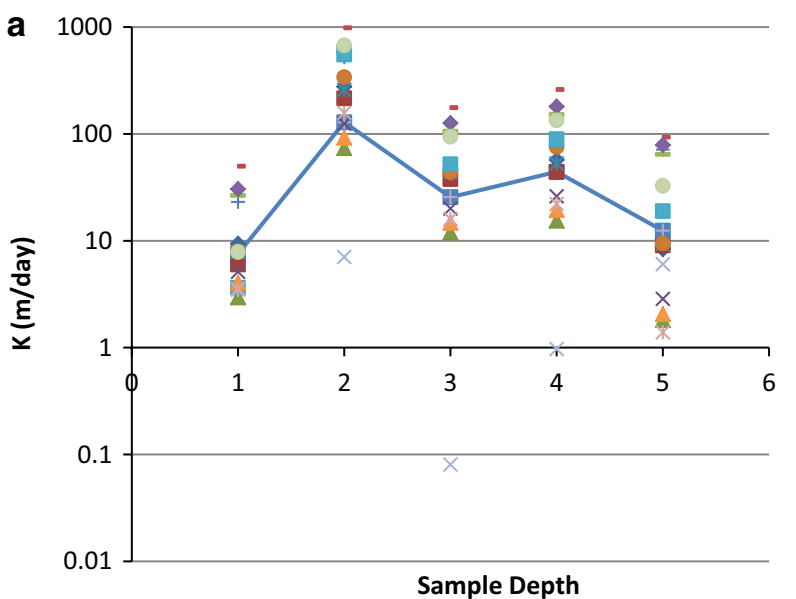

- Hazen
- Hazen K $(\mathrm{cm} / \mathrm{s})=\mathrm{d} 10(\mathrm{~mm})$
× Slichter
$\times$ Terzaghi
* Beyer
- Sauerbrei
+ Kruger
- Kozeny-Carmen
- Zunker
- Zamarin
- USBR

b

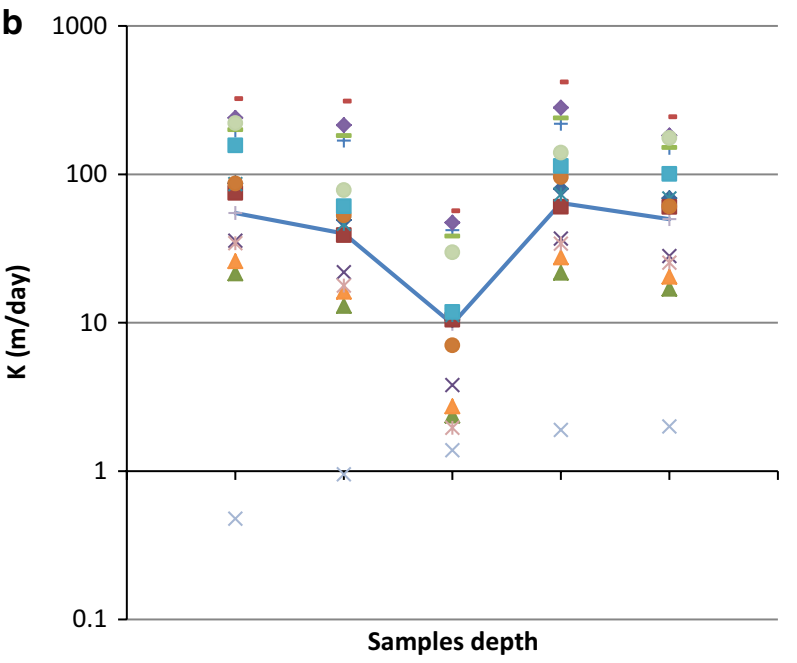

- Hazen

- Hazen $\mathrm{K}(\mathrm{cm} / \mathrm{s})=\mathrm{d} 10(\mathrm{~mm})$

- Slichter

$\times$ Terzaghi

* Beyer

- Sauerbrei

+ Kruger

- Kozeny-Carmen

- Zunker

- Zamarin

- USBR

$\triangle$ Barr

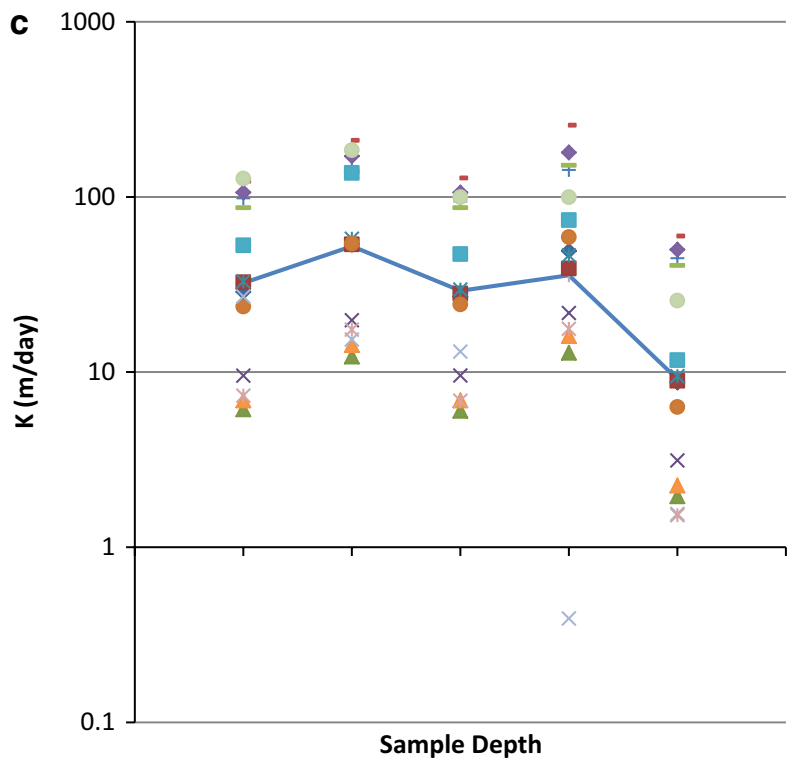

- Hazen

- Hazen $\mathrm{K}(\mathrm{cm} / \mathrm{s})=\mathrm{d} 10(\mathrm{~mm})$

- Slichter

$\times$ Terzaghi

* Beyer

- Sauerbrei

+ Kruger

- Kozeny-Carmen

- Zunker

- Zamarin

- USBR

$\triangle$ Barr

$\times$ Alyamani and Sen

* Chapuis
4 test wells (TW1-TW4) in the Lower Muda River Basin. The $K$ values of 114 samples collected from riverbank and 15 samples from streambeds were then estimated by using twelve grain-size empirical equation methods (Hazen, Hazen $K(\mathrm{~cm} / \mathrm{s})=d 10(\mathrm{~mm})$, Slichter, Terzaghi, Beyer, Sauerbrei, Kruger, Kozeny-Carmen, Zunker, Zamarin, USBR, Barr, 
Alyamani and Sen, Chapuis, and Krumbein and Monk. The alluvial system in the focused area was composed by six layers, namely upper sandy silt, silty sand, gravelly sand, a highly conductivity sandy gravel, gravelly sand and silty clay at the base. Further observations on the area discovered that the geometric mean of $K_{\mathrm{g}}$ for the sandy silt $(8.30 \mathrm{~m} /$ day), silty sand (47.66 m/day), gravelly sand ( $150.24 \mathrm{~m} /$ day), sandy gravel layer $(418.48 \mathrm{~m} /$ day $)$, gravelly sand $(151.09 \mathrm{~m} /$ day) and silty clay $(9.36 \mathrm{~m} /$ day $)$ as determined by grainsize analyses, was greater than the geometric mean obtained from pumping tests $(31.10 \mathrm{~m} / \mathrm{day})$. The geometric mean of $K$ estimates obtained from the performed permeability tests $(7.03 \mathrm{~m} /$ day $)$ was one to two orders of magnitude lower than that of pumping tests and grain-size analyses. As for the $K_{\mathrm{v}}$ values of the streambed for the upper layer of sediments, the values recorded were generally larger than those in their respective lower layer of sediments. The individual $K_{\mathrm{v}}$ value for the upper layer of sediments from all the tested locations of the left, right and middle rivers ranged from 7.56 to $54.77 \mathrm{~m} /$ day for upper layer, $39.8-128.4 \mathrm{~m} /$ day for middle layer and 9.11-49.92 m/day for lower layer of river, as produced by the grain-size analysis. Meanwhile, the $K_{\mathrm{v}}$ value ranged based on permeability test showed that the value of $K_{\mathrm{v}}$ started from 0.036 to $1.09 \mathrm{~m} /$ day for upper layer and $0.155-0.68 \mathrm{~m} /$ day for lower layer of river sediments. To understand this pattern, it should be firstly established that the value of $K_{\mathrm{v}}$ for streambed depends largely on hyporheic processes. The inflow and outflow of water through hyporheic zone produce more porous and permeable sediments that will then result in an increase in value of the streambed $K_{\mathrm{v}} . K$ estimates derived from the grain-size methods, permeability test and pumping tests were altogether compared in order to identify the $K$ values for numerical model. Based on the characteristics deduced from the outcomes, it is reasonable to conclude that the $K$ value of the aquifer in the focused area has the ideal $K$ value and potential. In addition, the area is proven to be showing suitable properties for riverbank filtration method to increase the water quality and water quantity of Lower Muda River Basin area.

The objective of this study was to compare the commonly utilised formulas in the establishment of $K$ value obtained from grain-size data and to evaluate the accuracy of these methods in predicting $K$ value in a highly deposition sediment. A large number of empirical and semi-empirical formulas that were initially chosen actually covered a wide range of different approaches to represent the effective grain size, shape and porosity functions. The comparison of 114 samples from riverbank and 15 samples from streambeds under the grain-size analysis not only prevailed a high degree of correlation between the tested formulas, but also highlighted how the calculated min, max and mean $K$ values may differentiate over several orders of magnitude between applied formulas. Based on the obtained results, it is clear that the outcomes demonstrated the need to test the reliability of calculated $K$ grain size with directly measuring $K$ values that are obtained with a method that employs a support volume similar to that of the grain-size analysis. Therefore, the permeability test and pumping test in situ $K$ characterisation were performed in the close vicinity of sampling points. There is a high correlation between $K$ value from grain-size analysis and $K$ value from permeability test seen for most of the applied formulas. The $K$ grainsize estimates were in most cases smaller than $K$ value of permeability test and $K$ value of pumping test estimates. To explain this, it is safe to say that this trend is attributed to the anisotropic distribution of $K$ in the sediments and how it reflects the differences between the measured in situ and the calculated $K$. In addition, the presence of isolated low $K$ layers with limited thickness within a high $K$ sample also leads to $K$ value of grain-size estimates that were significantly below the $K$ value from permeability test estimates. The calculated $K$ values are influenced by either the harmonic mean of the grain-size distribution, or certain grainsize diameter from the grain-size distribution curve. In comparison, the $K$ permeability values generally represent the arithmetic mean of the $K$ distribution within the test interval or layer. The general $K$ estimates for an initial assessment are proven necessary and that the calculation of $K$ from grainsize analysis is shown to be a suitable method. However, in this study, the value of $K$ grain-size data derived for aquifer characterisation has proven that it is sufficiently reliable for an assessment of $K$ variations and fitting to be observed in comparison with pumping test and permeability tests. With the publication of the underlying data, additional data from $K$ value will be provided and using the numerical modelling who are interested in developing or further evaluating methods in this field.

Acknowledgements The presented study was funded as part of the Ministry of Natural Resources and Environment (NRE) to this study under National Water Resources Council (P23101110117300). Many colleagues have contributed to this study. We would like to thank the staff of the National Hydraulic Research Institute of Malaysia (NAHRIM), for their technical assistance and for analysing the core samples.

Open Access This article is distributed under the terms of the Creative Commons Attribution 4.0 International License (http://creativeco mmons.org/licenses/by/4.0/), which permits unrestricted use, distribution, and reproduction in any medium, provided you give appropriate credit to the original author(s) and the source, provide a link to the Creative Commons license, and indicate if changes were made.

\section{References}

Alyamani MS, Sen Z (1993) Determination of hydraulic conductivity from complete grain-size distribution curves. Ground Water 31(4):551-555 
ASTM D2113-14 (2014) Standard Practice for Rock Core Drilling and Sampling of Rock for Site Exploration, ASTM International, West Conshohocken, PA

Barr DW (2001) Coefficient of permeability determined by measurable parameters. Ground Water 39(3):356-361

Bencala KE, Gooseff MN, Kimball BA (2011) Rethinking hyporheic flow and transient storage to advance understanding of stream catchment connections. Water Resour Res. https://doi. org/10.1029/2010WR010066

Beyer W (1964) Zur Bestimmung der Wasserdurchlässigkeit von Kiesen und Sanden aus der Kornverteilungskurve [Determination of the hydraulic conductivity of gravels and sands from particle distribution curves]. Wasserwirtsch Wassertech 14(6):165-168

Binley A, Ullah S, Heathwaite AL, Heppell C, Byrne P, Lansdown K, Trimmer M, Zhang H (2013) Revealing the spatial variability of water fluxes at the groundwater-surfacewater interface. Water Resour Res 49:3978-3992. https://doi.org/10.1002/wrcr.20214

Boadu FK (2000) Hydraulic conductivity of soils from grain-size distribution: new models. J Geotech Geoenviron Eng 126(8):739-746

Brunke M, Gonser T (1997) The ecological significance of exchange process between rivers and groundwater. Freshw Biol 37:1-33

Bruno MC, Maiolini B, Carolli M, Silveri L (2009) Impact of hydropeaking on hyporheic invertebrates in an Alpine stream (Trentino, Italy). Ann Limnol 45:157-170

Butler JJ, Zlotnik VA, Tsou MS (2001) Drawdown and stream depletion produced by pumping in the vicinity of a partially penetrating stream. Ground Water 39:651-659

Cardenas MB, Zlotnik VA (2003) A simple constant-head injection test for streambed hydraulic conductivity estimation. Ground Water 41(6):867-871

Carrier WD (2003) Goodbye, Hazen; hello, Kozeny-Carman. J Geotech Geoenviron Eng 129(111):1054-1056

Chapuis RP (2004) Predicting the saturated hydraulic conductivity of sand and gravel using effective diameter and void ratio. Can Geotech J 41:787-795

Chen XH (2000) Measurement of streambed hydraulic conductivity and its anisotropy. Environ Geol 39(12):1317-1324

Chen XH (2004) Streambed hydraulic conductivity for rivers in southcentral Nebraska. J Am Water Resour Assoc 40(3):561-574

Chen X (2005a) Statistical and geostatistical features of streambed hydraulic conductivities in the Platte River, Nebraska. Environ Geol 48:693-701

Chen XH (2005b) Statistical and geostatistical features of streambed hydraulic conductivities in the Platte River, Nebraska. Environ Geol 48(6):693-701

Chen XH (2007) Hydrologic connections of a stream-aquifer-vegetation zone in south-central Platte River valley, Nebraska. J Hydrol 333:554-568. https://doi.org/10.1016/j.jhydrol.2006.09.020

Chen X, Dong W, Ou G, Wang Z, Liu C (2013) Gaining and losing stream reaches have opposite hydraulic conductivity distribution patterns. Hydrol Earth Syst Sci 17:2569-2579

Cheng C, Chen XH (2007) Evaluation of methods for determination of hydraulic properties in an aquifer-aquitard system hydrologically connected to a river. Hydrogeol J 15:669-678

Cheong JY, Hamm SY, Kim HS, Ko EJ, Yang K, Lee JH (2008) Estimating hydraulic conductivity using grain-size analyses, aquifer tests, and numerical modeling in a riverside alluvial system in South Korea. Hydrogeol J 16:1129-1143

Chua LHC, Lo EYM, Freybery DL, Shuy EB, Lim TT, Tan SK, Ngonidzashe M (2007) Hydrostratigraphy and geochemistry at a coastal sandhill in Singapore. Hydrogeol J 15(8):1591-1604

Eggleston J, Rojstaczer S (2001) The value of grain-size hydraulic conductivity estimates: comparison with high resolution in-situ field hydraulic conductivity. Geophys Res Lett 28(22):4255-4258
Fox GA, DuChateau P, Durnford DS (2002) Analytical model for aquifer response incorporating distributed stream leakage. Ground Water 40:378-384

Freeze RA, Cherry JA (1979) Groundwater. Prentice Hall, Englewood Cliffs, p 604

Gariglio FP, Tonina D, Luce CH (2013) Spatio-temporal variability of hyporheic exchange through a pool-riffle pool sequence. Water Resour Res 49:7185-7204. https://doi.org/10.1002/wrcr.20419

Genereux DP, Leahy S, Mitasova H, Kennedy CD, Corbett DR (2008) Spatial and temporal variability of streambed hydraulic conductivity in West Bear Creek, North Carolina, USA. J Hydrol 358:332-353

Glover RE, Balmer GG (1954) River depletion resulting from pumping a well near a river. Trans Am Geophys Un Vol 35:468-470

Hancock PJ (2002) Human impacts on the stream-groundwater exchange zone. Environ Manag 29:763-781

Hantush MS (1965) Wells near stream with semipervious beds J. Geophys. Res. 70 2829-38 hard rock mines. Can Geotech J 33(3):470-482

Hazen A (1892) Some physical properties of sands and gravels, with special reference to their use in filtration. 24th annual report, Massachusetts State Board of Health, Springfield, pp 539-556

Hazen A (1893) Some physical properties of sand and gravels, with special reference to their use in filtration. Twenty Fourth Annual Report, State Board of Health of Massachusetts, pp 541-556

Hester ET, Gooseff MN (2010) Moving beyond the banks: hyporheic restoration is fundamental to restoring ecological services and functions of streams. Environ Sci Technol 44:1521-1525. https ://doi.org/10.1021/ess902988n

Hinsby K, Bjerg PL, Andersen LJ, Skov B, Clausen EV (1992) A mini slug test method for determination of a local hydraulic conductivity of an unconfined sandy aquifer. J Hydrol 1-4(136):87-106

Hunt B (1999) Unsteady stream depletion from ground water pumping. Ground Water 37(1):98-102

Hvorslev MJ (1951) Time lag and soil permeability in ground-water observations, Waterways Experiment Station, Corps of Engineers. US Army Bull 36:49

Indelman P, Moltyaner G, Dagan G (1999) Determining the hydraulic conductivity spatial structure at the Twin Lake site by grain-size distribution. Ground Water 37:223-227

Jha MK, Jayalekshmi K, Machiwal D, Kamii Y, Chikamori K (2004) Determination of hydraulic parameters of an unconfined alluvial aquifer by the floodwave-response technique. Hydrogeol J 12:628-642

Kalbus E, Reinstorf F, Schirmer M (2006) Measuring methods for groundwater, surface water and their interactions: a review. Hydrol Earth Syst Sci 10:873-887

Kasenow M (2002) Determination of hydraulic conductivity from grain size analysis. Water Resources Publications, LLC, Highlands Ranch, CO, pp 47-84

Kelly SE, Murdoch LC (2003) Measuring the hydraulic conductivity of shallow submerged sediments. Ground Water 41(4):431-439

Kennedy CD, Genereux DP, Corbett DR, Mitasova H (2009) Spatial and temporal dynamics of coupled groundwater and nitrogen fluxes through a streambed in an agricultural watershed. Water Resour Res 45:W09401. https://doi.org/10.1029/2008WR007397

Kozeny J (1927) Uber Kapillare Leitung Des Wassers in Boden. Sitzungsber Akad Wiss Wien Math Naturwiss K1 Abt 2a 13:271-306 (in German)

Kozeny J (1953) Das Wasser im Boden: Grundwasserbewegung (The water in the ground: groundwater flow). Hydraulik: ihre Grundlagen und praktische Anwendung. Springer, Heidelberg, pp $380-445$

Krüger E (1919) Die Grundwasserbewegung (Groundwater flow). Int Mitt Bodenkd 8:105-122 
Krumbein WC, Monk GD (1942) Permeability as a function of the size parameters of unconsolidated sand. Am Inst Min Metall Eng Trans 151:153-163

Landon MK, Rus DL, Harvey FE (2001) Comparison of instream methods for measuring hydraulic conductivity in sandy streambeds. Ground Water 39(6):870-885

Leek R, Wu JQ, Wang L, Hanrahan TP, Barber ME, Qiu H (2009) Heterogeneous characteristics of streambed saturated hydraulic conductivity of the Touchet River, south eastern Washington, USA. Hydrol Process 23:1236-1246

Mayer KU, Frind EO, Blowes DW (2002) Multicomponent reactive transport modeling in variably saturated porous media using a generalized formulation for kinetically controlled reactions. Water Resour Res 38(13):1-21

Packman AI, MacKay JS (2003) Interplay of stream-subsurface exchange, clay particle deposition and streambed evolution. Water Resour Res. https://doi.org/10.1029/2002WR001432

Reynolds, RJ (1987). Hydrogeology of the surficial outwash aquifer at Cortland, Cortland County, N.Y. U.S. Geological Survey Water Resources Investigation Report 85-4090, p 43

Rosas J, Lopez O, Missimer TM, Coulibaly KM, Dehwah AHA, Sesler K, Lujan LR, Mantilla D (2014) Determination of hydraulic conductivity from grain-size distribution for different depositional environments. Ground Water 52(3):399-413

Ryan R, Boufadel M (2007) Evaluation of streambed hydraulic conductivity heterogeneity in an urban watershed. Stoch Environ Res Risk Assess J 21(4):309-316

Schlichter CS (1899) Theoretical investigation of the motion of ground waters. US Geological Survey 19th Annual Report part 2, pp 295-384

Senthil Kumar M, Elango L (2001) Numerical simulation of groundwater flow regime in a part of the lower Palar River Basin, southern India. In: Elango L, Jayakumar R (eds) Modelling in hydrogeology. United Nations Educational, Scientific, and Cultural Organization International Hydrological Program-Allied, Paris, p 270

Shamsuddin MKN, Sulaiman WNA, Suratman S, Zakaria MP, Samuding K (2014) Groundwater and surface-water utilisation using a bank infiltration technique in Malaysia. Hydrogeol J 22:543. https://doi.org/10.1007/s10040-014-1122-4i:10.1007/s 1009 8-007-0143-2

Shamsuddin MKN, Suratman S, Zakaria MP, Aris AZ, Sulaiman WNA (2015) Using particle tracking as a tool sustainable bank infiltration techniques: a case study in an alluvial area. Arabian J Geosci $8(3): 1571-1590$
Shepherd RG (1989) Correlations of hydraulic conductivity and grain size. Ground Water 27(5):633-638

Slichter CS (1898) Theoretical investigations of the motion of ground waters. 19th annual report, US Geological Survey, Reston, VA, pp 295-384

Smith JWN (2005) Groundwater-surfacewater interaction in the hyporheic zone. Environment Agency-Science Report SC030155/SR1, Bristol

Song JX, Chen XH, Cheng C, Summerside S, Wen FJ (2007) Effects of hyporheic processes on streambed vertical hydraulic conductivity in three rivers of Nebraska. Geophys Res Lett 34:L07409. https:// doi.org/10.1029/2007GL029254

Song J, Chen X, Cheng C, Wang D, Lackey S, Xu Z (2009) Feasibility of grain-size analysis methods for determination of vertical hydraulic conductivity of streambeds. J Hydrol 375:428-437

Sophocleous MA, Koussis AD, Martin JL, Perkins SP (1995) Evaluation of simplified stream-aquifer depletion models for water rights administration. Ground Water 33(4):579-588

Spalding CPP, Khaleel R (1991) An evaluation of analytical solutions to estimate drawdown and stream depletion by wells. Water Resour Res 27:597-609

Springer AE, Petroutson WD, Semmens BA (1999) Spatial and temporal variability of hydraulic conductivity in active reattachment bars of the Colorado River, Grand Canyon. Ground Water 37(3):338-344

Terzaghi K (1925) Principles of soil mechanics. Eng News-Rec 95:832-836

Theis CV (1941) The effect of a well on the flow of a nearby stream. EOS Trans Am Geophys Union 22:734-738

Uma KO, Egboka BCE, Onuoha KM (1989) New statistical grain-size method for evaluating the hydraulic conductivity of sandy aquifers. J Hydrol 108:343-366

Vukovic M, Soro A (1992) Determination of hydraulic conductivity of porous media from grain-size composition (Miladinov D, Trans) Water Resources Publications, Littleton

Winter TC (1998) Groundwater and surfacewater: a single resource. Diane, Darby

Zamarin JA (1928) Calculation of ground-water flow. Trudey I.V.H, Taskeni (in Russian)

Zunker F (1930) Das Verhalten des Wassers zum Boden (The behavior of groundwater). Zeitschr Pflanzenernäh Düng Bodenkd A25(1):7

Publisher's Note Springer Nature remains neutral with regard to jurisdictional claims in published maps and institutional affiliations. 